\title{
The "Matthew Effect" and Market Concentration: Search Complementarities and Monopsony Power
}

\author{
Jesús Fernández-Villaverde, Federico S. Mandelman, \\ Yang $\mathrm{Yu}$, and Francesco Zanetti
}

\section{Working Paper 2021-4 \\ January 2021}

\begin{abstract}
This paper develops a dynamic general equilibrium model with heterogeneous firms that face search complementarities in the formation of vendor contracts. Search complementarities amplify small differences in productivity among firms. Market concentration fosters monopsony power in the labor market, magnifying profits and further enhancing the output share of high-productivity firms. The combination of search complementarities and monopsony power induce a strong "Matthew effect" that endogenously generates superstar firms out of uniform idiosyncratic productivity distributions. Reductions in search costs increase market concentration, lower the labor income share, and increase wage inequality. The model also transforms short-lived negative aggregate shocks into persistent recessions that heighten market concentration.
\end{abstract}

JEL classification: C63, C68, E32, E37, E44, G12

Key words: market concentration, superstar firms, search complementarities, monopsony power in the labor market

https://doi.org/10.29338/wp2021-04

\footnotetext{
The authors gratefully acknowledge Michael Peters for an outstanding discussion and most helpful suggestions to simplify our analysis, as well as Luis Garicano and Gustavo Ventura for insightful comments. Ryan Zalla provided outstanding research assistance. Zanetti gratefully acknowledges financial support from the British Academy. The views expressed in this paper are solely the responsibility of the authors and should not be interpreted as reflecting the views of the Federal Reserve Bank of Atlanta or the Federal Reserve System. Any remaining errors are the authors' responsibility.
}

Please address questions regarding content to Jesús Fernández-Villaverde, University of Pennsylvania, 133 South 36th Street, Philadelphia, PA 19104, jesusfv@econ.upenn.edu; Federico Mandelman, Federal Reserve Bank of Atlanta, 1000 Peachtree Street NE, Atlanta, GA, 30309, federico.mandelman@atl.frb.org; Yang Yu, Shanghai University of Finance and Economics, 318 Wuchuan Road, Shanghai, China, yu.yang@mail.shufe.edu.cn; or Francesco Zanetti, University of Oxford, Manor Road, Oxford, OX1 3UQ, United Kingdom, francesco.zanetti@economics.ox.ac.uk.

Federal Reserve Bank of Atlanta working papers, including revised versions, are available on the Atlanta Fed's website at www.frbatlanta.org. Click "Publications" and then "Working Papers." To receive e-mail notifications about new papers, use frbatlanta.org/forms/subscribe. 


\section{Introduction}

Merton (1968) famously identified the "Matthew effect": For whoever has will be given more, and they will have an abundance. Whoever does not have, even what they have will be taken from them. Merton's insight was straightforward: small exogenous differences get amplified, often by orders of magnitude, by the endogenous responses of agents to those small differences. For instance, in Merton's original analysis, small differences in scientific productivity are magnified by the extreme inequality in the allocation of limited resources (grant money, graduate students, journal pages). Imagine a national research agency that only has money to finance one research lab, but can correctly identify ex-ante differences in scientific productivity among professors. Even if professor $\mathrm{A}$ is just $1 \%$ more productive than professor B, professor $\mathrm{A}$ will get the funds to run a lab, become famous and influential. In contrast, professor B will linger in obscurity.

In this paper, we argue that a "Matthew effect" drives the high levels of market concentration observed in the data, with a few superstar firms and many small firms, even when the differences in productivity among firms are minor. The "Matthew effect" operates through strategic complementarities under direct search and monopsony power in the labor market.

Let us unpack these mechanisms. Firms need to sign vendor contracts with their suppliers before producing. This process involves costly search. If you are going to operate an ice cream truck company, you need to find a supplier of milk, a supplier of waffle cones, a supplier of toppings, a supplier of ice cream mixers, a supplier of trucks, etc. This search is costly in time and resources. ${ }^{1}$

Intermediate-goods suppliers search with higher effort when they are more productive because the potential profit from a vendor match is larger. For example, a high-productivity waffle cone manufacturer will pay the costs in time and resources of attending a trade fair for the restaurant industry, but a low-productivity manufacturer will not. Conversely, final-goods producers send more buying agents when they know that the intermediate-goods suppliers are searching for buyers. This decision is particularly salient with directed search: i.e., the ice cream company receives a directory of the booths in the trade fair and, upon seeing that a high-productivity waffle cone producer is attending the fair, sends an agent to visit that booth right away.

\footnotetext{
${ }^{1}$ This example is taken from the fascinating tale of how Mister Softee tried and failed to establish an ice cream business in Suzhou in the 2000s. See https://supchina.com/podcast/ the-rise-and-fall-of-a-suzhou-soft-serve-baron/.
} 
Hence, high-productivity intermediate-goods vendors will form more matches with final-goods firms. In the terminology of Bulow et al. (1985), a strategic complementarity appears because the stronger the search of the intermediate-goods producers, the stronger the directed search of the final-goods firms and vice versa.

The search complementarity mechanism will induce a highly concentrated distribution of firms' size, vacancies, and output. In particular, small differences in productivities among intermediate-good firms will result in large differences in firms' size and output. Interestingly, this "Matthew effect" transforms a uniform distribution of idiosyncratic productivity into a highly skewed firm's distribution characterized by the presence of superstar firms. In contrast with most of the literature, we do not need fat tails in the distribution of firms' idiosyncratic properties (e.g., productivity, demand shifters, etc.) to generate this result.

The process, however, does not end up here. In our model, there is a second mechanism reinforcing the "Matthew effect": the labor market power of large firms. If firm A is the waffle cone producer in a region, it has market power when hiring bakers. This market power creates two effects. First, more productive firms will pay higher wages (as we observe in the data): the surplus of a labor match is larger and the worker will receive part of it. However, conditional on productivity, the wages will be a lower share of the surplus. That is, large firms will have a lower labor income share (again, as we see in the data). The higher the market power, the stronger these two effects will be.

This labor market power will also have a consequence for search under strategic complementarities. Since larger firms will keep a higher share of the surplus of a labor match, larger firms will also have a stronger incentive to search with more intensity (beyond the direct effect of higher productivity). That higher search intensity will be reinforced by the response of final-good producers. That is, search complementarities transform labor market power into significant differences in the market structure and firms' sizes and output.

The mechanisms outlined above also have significant business cycle implications. After a negative aggregate productivity shock, firms will decrease their search effort. This fall in search effort will amplify the original shock and make it more persistent over time. Furthermore, the reduction in aggregate productivity will affect low-productivity firms disproportionately because their profit margins are smaller. Thus, low-productivity firms will reduce their search effort more than high-productivity firms, leading to more market concentration. 
To explore these mechanisms formally, we first develop a simple model that isolates the effect of search complementarities and monopsony power for the distribution of firms, market concentration, and the effect of aggregate shocks. The model will not be designed for quantitative work, but it illustrates all our ideas transparently.

Next, we build a dynamic general equilibrium model with heterogeneous firms and frictional labor markets. At the core of our model, we embed the integration of complex production processes that require long-lasting vendor relations among different intermediate- and final-goods firms. This assumption is motivated by the strong empirical evidence on the existence of sophisticated multi-firm value-chains. In the model, the intermediate-goods firms manage a continuum of product lines and search for buyers of those goods. Final-goods producers assign buying agents to find those product lines and sign contracts with them. The two-sided search among firms leads to strategic complementarities: intermediate-goods firms' optimal search effort increases with the visits of final-goods producers' buying agents, and vice versa.

Our model is enriched with monopsony power in the labor market by adding search and matching frictions that let firms to set wages below the marginal product of labor. To do so, we consider a matching technology in the labor market à la Butters (1977), which allows multiple workers to apply to a single vacancy randomly. This environment provides the firm with the power to select one worker among multiple job applicants. A firm operating in concentrated markets can induce workers to accept a low wage since it could threaten the worker to forgo future job offers if the worker declines a wage offer. Intuitively, if just a limited number of firms dominate a segment of the labor market, a prospective employee that rejects a job offer may be excluded de facto from future consideration since the firm will prefer other job applicants. Top firms exploit their market power to offer a low wage and gain profits, which in turn increases profits and encourages firms with market power to search more actively and attract more visits from potential partners. Labor market power enhances search complementarities in the goods market and it is a critical force to generate market concentration.

We calibrate the model to match quarterly U.S. data and then use it as a measurement device. Given that we want to be consistent with the differences in measured total factor productivity across manufacturing plants, the rate of factory idleness, and labor market observations, how much monopsony power do we need to account for market concentration by the top $10 \%$ of firms? From this exercise, we back up what we judge as a mild form of monopsony power: the 
equivalent of firms being able to punish workers that reject an offer by turning down their future applications for around six months. This reasonable degree of monopsony power enhances our trust in the model as a quantitative laboratory for further exercises.

How can we use our model to think about the recent experience of advanced economies? Several studies have documented a steady increase in market concentration over the past three decades. For example, Autor et al. (2020) show that, starting in the early 1980s, sales moved towards the most productive firms across U.S. industries. At the same time, labor markets became increasingly dominated by fewer players, lowering the bargaining power of workers and deepening income inequality (Wu, 2019). Monopsony power in labor markets has also boosted firm profits and market concentration (Hershbein et al., 2020). Furthermore, the early 1980s witnessed the outset of the Great Moderation, a sustained period with low volatility.

Our model presents a simple mechanism to jointly account for all these observations: a fall in the costs of signing vendor contracts. While all firms increase their search effort when the costs of signing vendor contracts fall, high-productivity firms make a disproportionate gain out of this change, as their search effort decisions are much more non-linear on search costs than those of low-productivity firms. Thus, in our model, lower search costs lead to i) higher market concentration, ii) lower labor income shares, iii) more labor market power, and iv) lower responses of output to aggregate shocks. We observe the same four facts in U.S. data.

What do we have in mind in terms of lower search costs? Improvements in IT technology. The internet has made it much easier to identify vendors and suppliers, to manage them, to run logistics and inventories, to handle sophisticated value-added chains, etc.

While market structure changes the response of the economy to aggregate shocks, the effect also works in the opposite direction: the market structure is endogenously determined by the realization of aggregate shocks. The persistently low search effort and output by lowproductivity firms after a large negative aggregate shock result in an increasing market exit among the production lines owned by these firms. As a result, deep slumps render the market-structure increasingly concentrated.

This behavior also matches the empirical evidence. Using U.S. Census firm-level panel data, Salgado et al. (2019) show that business cycles are skewed. That is, during recessions, a subset of firms significantly underperforms, leading to a large fat left tail in the production distribution. The process is reversed in expansions, when the right tail becomes fatter. 
The market concentration effect of negative aggregate shocks also appears in the customer base literature. Chevalier and Scharfstein (1996) find that, during recessions, small (and liquidity constrained) firms invest less in expanding their customer base and raise prices to boost their liquidity positions. Bigger firms expand their customer base in recessions, which renders the market more concentrated afterward. Investment in customer base resembles network formation in the context of our model.

Our paper connects with many other different areas of research. First, and most importantly, there is a tradition of papers exploring the firm's size distribution that goes back to the span-ofcontrol model by Lucas (1978). One can think about our theory as an endogenous determinant of the span-of-control: production links must be formed either within firms or between firms. Directed search and strategic complementarities determine how many of these links are created in our model.

Our theory has two advantages with respect to a simple span-of-control model. First, we can generate larger dispersion in firms size that is compatible with observed differences in measured total factor productivity across plants. Second, our model allows us to have a simple margin to account for the simultaneous increase in market concentration and fall of the labor income share: the reduction in direct search costs, which we link with observed improvements in IT. In a simple span-of-control model, one would need to resort to either production functions getting closer to linear or a change in the underlying distribution of managerial talent to generate similar outcomes (see, however, for more flexible versions of the span-of-control model, Garicano and Rossi-Hansberg, 2006).

Linked with the Lucas' tradition, there is much recent research focused on growing market concentration. Aghion et al. (2019) find that IT explains the lower cost of production for bigger firms, with newer firms (or less efficient ones) finding increasing difficulty to contest them. Similarly, Akerman et al. (2013), Bessen (2017), and Unger (2019) attribute this winner-takes-all mechanism to economies of scale arising from intangible capital and advances in information technology, which greatly improve the product and inventory logistics.

A second strand of the literature has been devoted to understanding the recent decline in the labor share of output. See, among many others, Elsby et al. (2013), Karabarbounis and Neiman (2014), and references therein. De Loecker and Eeckhout (2018) attributes this phenomenon to a raise in weighted average firm markups, with Gutiérrez and Philippon (2018) emphasizing the 
role of weakening antitrust U.S. enforcement. Closer to our work is Autor et al. (2020), who argue that the decline in the labor share should be attributed to the reallocation of market share towards "superstar" firms with higher markups. Consistent with this hypothesis Peters (2020) find that markups vary systematically across firms, with incumbents investing to increase productivity growth (further raising markups). However, a creative destruction mechanism also exists in this last paper, as new and more efficient firms displace incumbents. Higher entry costs or frictions may thus deter this key pro-competitiveness mechanism.

Third, our paper also contributes to the growing theoretical literature of monopsony in labor markets, which is generated through diverse mechanisms. Examples include Ashenfelter et al. (2010), Berger et al. (2019), Manning (2011), Card et al. (2018); and Lamadon et al. (2019). In turn, empirical papers finding substantial market power in the labor market include Azar et al. (2019), Saiger et al (2010), Falch (2010); Ransom and Sims (2010) and Matsudaira (2014)).

Fourth, starting with seminal contributions of Diamond (1982) and Weitzman (1982), several papers have linked strategic complementarities to aggregate fluctuations. See, without being exhaustive, Diamond and Drew Fudenberg (1989), Huo and Ríos-Rull (2013),Kaplan and Menzio (2016), and Taschereau-Dumouchel and Schaal (2015). We depart, though, from those papers in our focus on how strategic complementarities and monopsony power create a "Matthew effect" on market concentration and analyze how those mechanisms interacts with aggregate shocks.

Finally, in Fernández-Villaverde et al. (2019), we explore how fiscal policy and strategic complementarities interplay to explain the persistence of both the business cycle and the unemployment rate. Our previous work abstract, however, from firm heterogeneity, market concentration, and monopsonistic labor markets. It focuses, instead, on the possibility of multiple equilibria, which do not play any role in the current paper.

The remainder of the paper is structured as follows. Section 2 develops a simple model to outline the main ideas in our paper. Section 3 extends the simple model to a more fleshed-out dynamic general equilibrium model. Section 4 calibrates the model to U.S. data and uses it to measure monopsony power in the labor market. Section 5 presents our quantitative findings. Section 6 concludes. 


\section{A simple model}

We start our analysis by presenting a simple model, with a closed-form solution, that embodies the central mechanisms we want to explore. The model incorporates an interplay between directed search and endogenous search effort that begets search complementarities. We will extend this simple model along two dimensions. First, we will incorporate endogenous variations in market concentration through the entry and exit of product lines. Our second extension will introduce monopsony power in the labor market to evaluate how such a power interrelates with market concentration.

While neither the simple model nor its two extensions are designed for quantitative work (we will impose restrictive functional forms and parametric choices), the mechanisms that drive the results above are transparent. In Section 3, we will present an extended model that give us quantitative predictions.

\subsection{Environment}

Time is discrete and infinite. The economy is composed of $J+1$ islands. Each island $j \in$ $\{1,2, \ldots, J\}$ hosts an intermediate-goods producer $(I)$, such as General Mills or Kellogg's. Each intermediate-goods producer operates a unitary measure of product lines, such as the many food brands manufactured by General Mills, and has an idiosyncratic productivity shock $x_{j}$. The central island $J+1$ hosts a representative household and a final-goods producer $(F)$, such as Walmart, that purchases food items from General Mills.

The intermediate-goods producers and the final-goods producer must form a vendor relation before starting production, e.g., General Mills will not produce breakfast cereals if it does not have access to a supermarket to sell them. The intermediate-goods producer either does not have the technology to reach consumers directly or that is too costly for it to do so. In fact, General Mills and similar firms do not sell to final consumers.

The process of search to form vendor relations is directed. At the start of each period $t$, the firm $F$ decides how many buying agents to send to each island to maximize its total profits. The firm $F$ can pick any positive real number of buying agents.

Production begins when a buying agent from firm $F$ signs a contract with a single product line in the firm $I$. In our example, Walmart decides how many buying agents to send to General 
Mills. Each Walmart buying agent will work with a General Mills' brand manager to reach a vendor contract for that brand. The more buying agents Walmart sends, the more contracts can be signed. ${ }^{2}$ The number of active product lines is equal to the number of buying agents that sign a contract. The total output for each signed contract is $2 z_{t} x_{j}$, where $z_{t}$ is an aggregate productivity shock in period $t$. Output is equally split between firm $F$ and $I$.

Buying agents who fail to sign a contract with a product line in firm $I$ withdraw from the island, while the unmatched product line of firm $I$ stays idle for the period. A law of large numbers holds in the economy and, thus, probabilities equate realized shares. That is, if the equilibrium implies a 0.32 probability of meeting in any island $j$, a match occurs in $32 \%$ of product lines in this island.

The representative household owns all the firms in the economy, receives the aggregate net profits from them, and consumes them. Since our focus is on the consequences of firm heterogeneity, the representative household assumption simplifies our analysis.

At the end of each period $t$, all the vendor matches are dissolved, buying agents from firm $F$ return to their headquarters, and the searching process restarts ex novo in period $t+1$. This assumption transforms the dynamic programming problem of the firms into a sequence of static optimization problems. Figure 1 summarizes the structure of the economy.

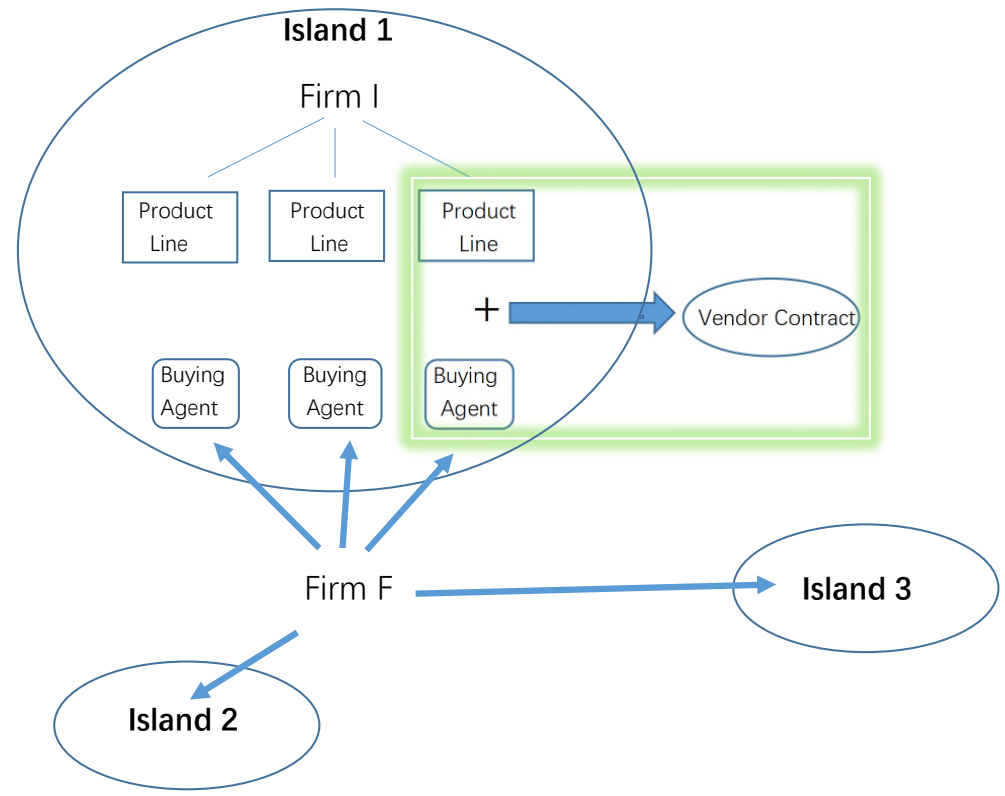

Figure 1: Structure of the economy

\footnotetext{
${ }^{2}$ This buying agent, in real life, is a bundle of different workers (from logistics, legal, marketing). For our purposes, we can ignore that margin since we only care about is Walmart's total buying cost.
} 
A matching function determines the probability of meeting and signing a vendor contract. The likelihood of matching in each island $j$ depends on the measure of buying agents from firm $F, n_{j}^{F}$, the measure of product lines owned by firm $I, n_{j}^{I}$, and the effort firm $I$ exerts in finding a buying agent from firm $F, \sigma_{j}^{I} \in[0,1]$ (to save on notation, we will only use a subindex $t$ for a variable when needed to avoid confusion). More precisely, the measure of newly formed matches is established by a matching function that is affine on $\sigma_{j}^{I}$ and Cobb-Douglas between $n_{j}^{F}$ and $n_{j}^{I}$ :

$$
M\left(\sigma_{j}^{I}, n_{j}^{I}, n_{j}^{F}\right)=\phi \sigma_{j}^{I}\left(n_{j}^{F}\right)^{\frac{1}{2}}\left(n_{j}^{I}\right)^{\frac{1}{2}}
$$

Since we assume that $n_{j}^{I}=1$, the matching probabilities for firm $F$ and $I$ are $\pi^{I}\left(\sigma_{j}^{I}, n_{j}^{F}\right)=$ $\phi \sigma_{j}^{I}\left(n_{j}^{F}\right)^{\frac{1}{2}}$ and $\pi^{F}\left(\sigma_{j}^{I}, n_{j}^{F}\right)=\phi \sigma_{j}^{I}\left(n_{j}^{F}\right)^{-\frac{1}{2}}$, respectively. Similarly, the matching probability for each product line of firm $I$ is $M\left(\sigma_{j}^{I}, n_{j}^{I}, n_{j}^{F}\right) / n_{j}^{I}$ and for each buying agent $M\left(\sigma_{j}^{I}, n_{j}^{I}, n_{j}^{F}\right) / n_{j}^{F}$.

Output in each island $j$ is:

$$
y_{j}=2 \phi \sigma_{j}^{I}\left(n_{j}^{F}\right)^{\frac{1}{2}} z_{t} x_{j}
$$

The cost of search effort for firm $I$ in island $j \in\{1,2, \ldots, J\}$ is:

$$
c\left(\sigma_{j}^{I}\right)=\frac{\left(\sigma_{j}^{I}\right)^{3}}{3} .
$$

We pick a power of 3 in the function above for algebraic convenience, but all we need is convexity of the search cost.

The firm $F$ pays a unit cost of sending buying agents equal to $\kappa$, which we normalize to $\kappa=\phi / 2$. Thus, the consumption that the representative household gets from island $j$ is:

$$
c_{j}=2 \phi \sigma_{j}^{I}\left(n_{j}^{F}\right)^{\frac{1}{2}} z_{t} x_{j}-\frac{\left(\sigma_{j}^{I}\right)^{3}}{3}-\kappa n_{j}^{F} .
$$

\subsection{Nash equilibria}

To find the Nash equilibria in our model, we consider the problem of firm $I$ in island $j$ that takes the measure of buyers from sector $F$ on its island, $n_{j}^{F}$, as given. The profit function for firm $I$ is:

$$
J\left(\sigma_{j}^{I}, n_{j}^{F} \mid x_{j}, z_{t}\right)=\phi \sigma_{j}^{I}\left(n_{j}^{F}\right)^{1 / 2} z_{t} x_{j}-\frac{\left(\sigma_{j}^{I}\right)^{3}}{3} .
$$


Maximizing $J\left(\sigma_{j}^{I}, n_{j}^{F} \mid x_{j}, z_{t}\right)$ with respect to $\sigma_{j}^{I}$, we obtain the best response function for firm $I$ in island $j$ :

$$
\sigma_{j, t}^{I}=\sqrt{\phi \widehat{n}_{j}^{F} z_{t} x_{j}}
$$

where, to simplify notation, we have defined $\widehat{n}_{j}^{F} \equiv\left(n_{j}^{F}\right)^{1 / 2}$.

Let us consider now the problem of firm $F$. Since the search process in the intermediategoods market is directed, the firm $F$ sends enough buyers to visit island $j$ to exploit all profit opportunities. Hence, the firm $F$ 's income from sending an additional buying agent to an island (the matching probability times the revenue per signed contract) is equal to the unit cost of sending the agent $\kappa$, which we normalize to $\kappa=\phi / 2$ :

$$
\widehat{n}_{j}^{F}=\sigma_{j}^{I} z_{t} x_{j}
$$

Equations (4) and (5) show why we have (strategic) search complementarities in the sense of Bulow et al. (1985): firm I's search effort is (weakly) increasing in firm F's number of buying agents (equation 4) and firm F's number of buying agents is an affine function of firm I's search effort (equation 5). An increase in search effort from firm $I$ on island $j$ increases the profits for firm $F$ and, thus, attracts a larger measure of buying agents on the island, raising the profits for firm $I$ and further stimulating search effort.

Directed search is at the core of this result: firm F's decision depends on firm $I$ in island $j$ 's search effort because firm $F$ can direct its buying agents to island $j$. With random search, an increment in the search effort of firm $I$ in island $j$ would only affect firm $F$ 's decision by changing the revenue of an additional contract in island $j$ times the probability that the additional buying agent would arrive at the island. When $J$ is large, the effect would be negligible.

A (within period and island) pure strategy Nash equilibrium is a tuple $\left\{\sigma_{j}^{I}, \widehat{n}_{j}^{F}\right\}$ that is a fixed point of (4) and (5). The system has two Nash equilibria in pure strategies. One Nash equilibrium, $\left\{\sigma_{j}^{I}, \widehat{n}_{j}^{F}\right\}=\{0,0\}$, is not very interesting and we will ignore it. Also, at the cost of some extra notation, we could assume that a minimum number of matches occur even when $\sigma_{j}^{I}=0$ and this equilibrium would disappear.

The other equilibrium is $\left\{\sigma_{j}^{I}, \widehat{n}_{j}^{F}\right\}=\left\{\phi z_{t}^{2} x_{j}^{2}, \phi z_{t}^{3} x_{j}^{3}\right\}$. Then, equation (1) implies that the

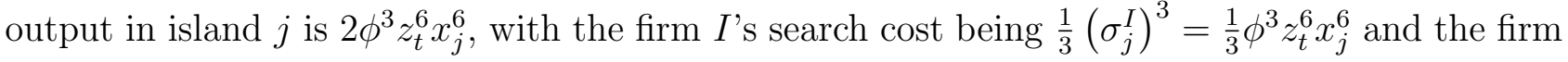
F's search cost $n_{j}^{F} \kappa=\frac{1}{2} \phi^{3} z_{t}^{6} x_{j}^{6}$. Thus, consumption, $c_{j}$, after the search costs, is $\frac{7}{6} \phi^{3} z_{t}^{6} x_{j}^{6}$. 
By summing over the islands, we get the aggregate output $y_{t}$ :

$$
y_{t}=2 \phi^{3} z_{t}^{6} \sum_{j=1}^{J} x_{j}^{6}
$$

and aggregate consumption $c_{t}=\frac{7}{6} \phi^{3} z_{t}^{6} \sum_{j=1}^{J} x_{j}^{6}$.

Equation (6) reveals how a $\Delta$ difference in productivity (either at the island or aggregate level) leads to a $\Delta^{6}$ difference in output. The degree of amplification, 6 , is determined by the curvature of the search cost function (equation 2). We can increase or decrease the amplification effect by adjusting the search cost function.

To illustrate these derivations, we fix the number of islands $j$ to 3 for the rest of this section. We set $\phi=0.5^{1 / 3}$, which implies that, when $z_{t} x_{j}=1$, the matching probability for firm $I$ is 0.5 . For the moment, $z_{t}=1$. With this choice of parameter values, output in island $j$ is $x_{j}^{6}$. Just for simplicity, we assume that productivity across islands is $x_{1}=0.95, x_{2}=1$, and $x_{3}=1.05$.
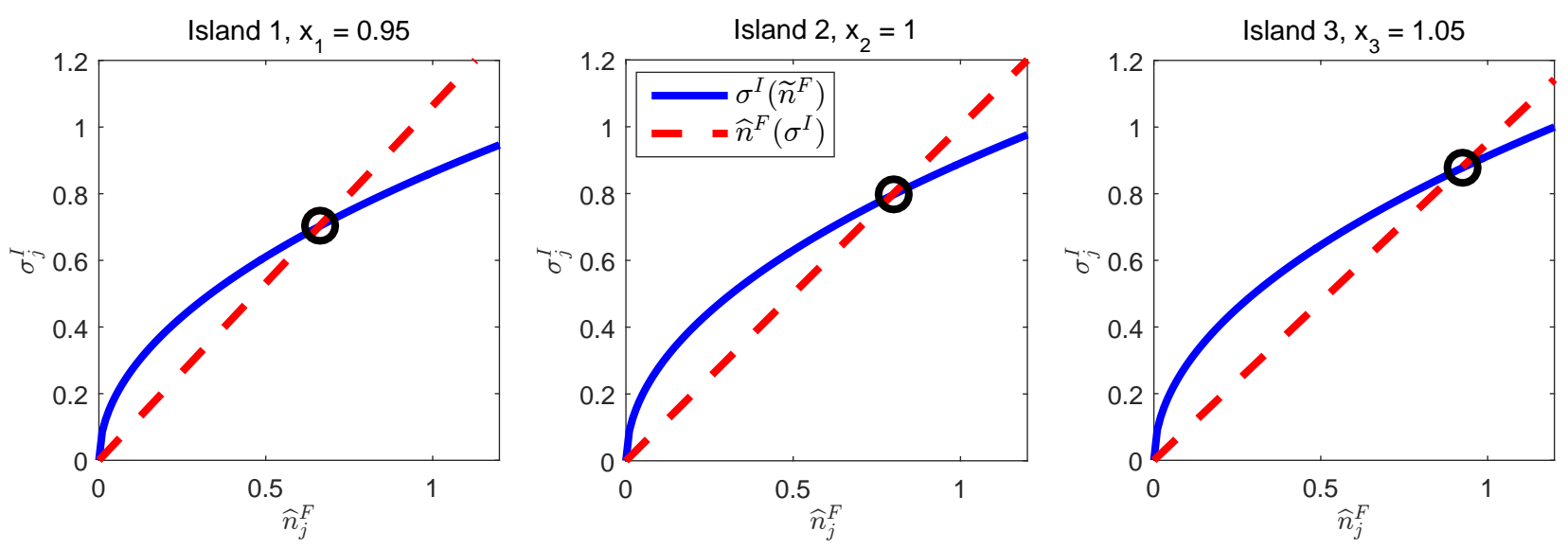

Figure 2: Nash equilibria across islands

Figure 2 plots the best response function of firm $I$ in each island (continuous blue line) and the optimality condition of firm $F$ regarding the number of buying agents sent to the island (discontinuous red line). In the left panel, we plot the functions for island 1; in the center panel, we plot the functions for island 2 ; and in the right panel, we plot the functions for island 3 . The circle markers plot the Nash equilibria, $\left\{\sigma_{j}^{I}, \widehat{n}_{j}^{F}\right\}$, for each island.

As implied by equations (4) and (5), a higher productivity triggers strong strategic complementarities and a "Matthew Effect" of degree 6. While island 3 is only $10.5 \%$ more productive than island 1, it exerts $22 \%$ more search effort and attracts $35 \%$ more visits from firm $F$ than 
island 1, which generates an output $82 \%$ larger. Specifically, $\left(\sigma_{1}^{I}, \widehat{n}_{1}^{F}, y_{1}\right)=(0.72,0.68,0.74)$, in comparison with $\left(\sigma_{3}^{I}, \widehat{n}_{3}^{F}, y_{3}\right)=(0.88,0.92,1.34)$.

A similar amplification phenomenon appears after an aggregate productivity shock. The left panel of Figure 3 plots a one-period aggregate productivity shock that decreases $z_{t}$ from its original value of 1 to 0.95 in the second period and fully recovers in the third period. The right panel of Figure 3 plots the impulse-response function (IRF) of output to the shock in the left panel in each of our three islands. Again, we can see the amplification: a reduction of $5 \%$ of aggregate productivity results in a $26 \%$ fall in output. Given the strong parametric assumptions we have made to get closed-form solutions, the reduction of output is uniform across islands. This uniformity is easy to break by introducing, for instance, fixed costs.
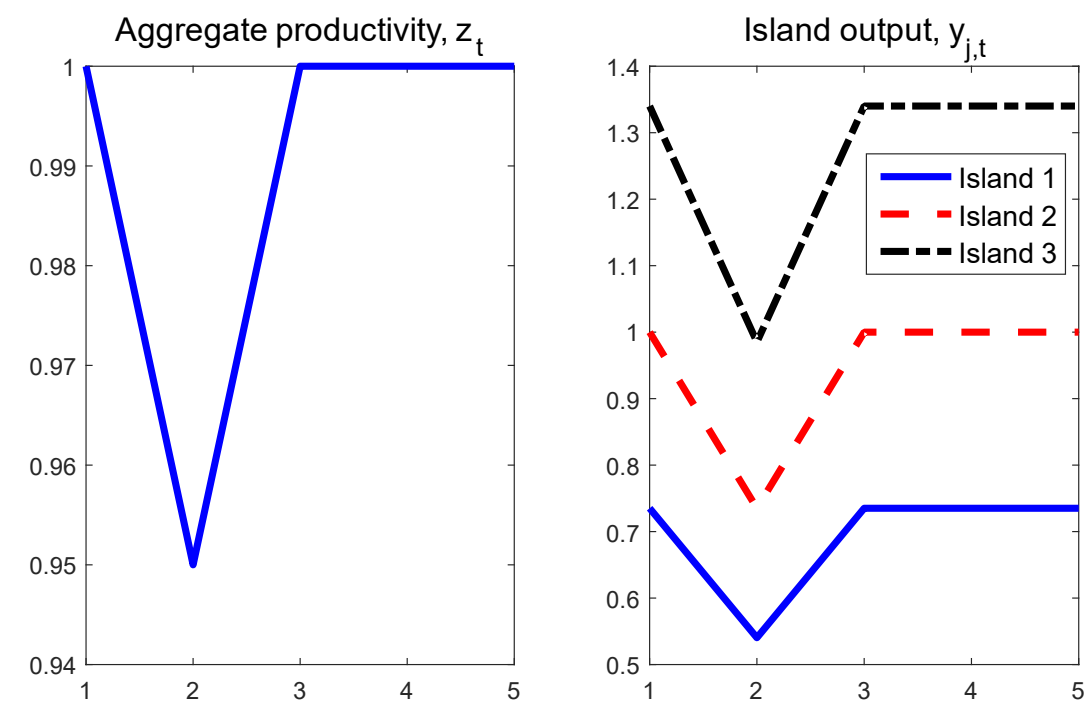

Figure 3: IRFs to negative aggregate productivity shock

Figure 2 and 3 take the distribution of island size as exogenous. Next, we endogenize market concentration by allowing for entry and exit of product lines and show that the "Matthew Effect" becomes even more potent.

\subsection{Endogenous market concentration}

Now, we enrich our simple model by introducing entry and exit of product lines for intermediategoods firms $I$. The entry and exit margin will deliver three new results: i) the "Matthew effect" becomes even more prominent than before; ii) market concentration will depend on the cost of signing a vendor contract; and iii) aggregate productivity shocks change market concentration 
of vendor contracts on each island (i.e., the size distribution of firms $I$ ) and make the effects of short-lived aggregate shock highly persistent.

We assume that unmatched product lines of the firm in sector $I$ in each island $j$ become obsolete and exit the economy with probability $\chi$. Conversely, new product lines are created at the constant rate $n$ in each period $t$. This assumption can be micro-founded with a fixed operation cost with a cash-on-hand constraint: in the absence of a positive cash flow, the product line is forced to close. To simplify, we will assume that firms decide on search effort without accounting that foregoing a match may make them obsolete in the next period (we will remove this simplification in the extended in Section 3). For simplicity, the entry rate is exogenous. Our results hold, with heavier notation, if entry is endogenous.

The measure of product lines in each island $j$ follows the law of motion:

$$
n_{j, t+1}^{I}=n_{j, t}^{I}-\underbrace{\chi \cdot\left[1-\pi^{I}\left(\sigma_{j, t}^{I}, \widehat{n}_{j, t}^{F}\right)\right] n_{j, t}^{I}}_{\text {Exit }}+\underbrace{n}_{\text {Entry }}
$$

where $\chi \cdot\left[1-\pi\left(\sigma_{j, t}^{I}, \widehat{n}_{j, t}^{F}\right)\right]$ is the fraction of unmatched product lines that exit island $i$, and $n$ is the measure of new entrance of product lines. The measure $n_{j, t+1}^{I}$ increases in the matching probability $\pi^{I}\left(\sigma_{j, t}^{I}, \widehat{n}_{j, t}^{F}\right)$. Thus, the exit rate for product lines is lower in an island with higher probability of establishing a vendor contract with firm $F$, leading to a subsequent higher measure of active product lines in the island. Equation (7) implies that the steady-state measure of product lines is:

$$
n_{j}^{I}=\frac{n}{\chi \cdot\left(1-\pi_{j}^{I}\right)}
$$

We set $\chi=0.282$ to generate a steady-state measure of product lines in island 3 of 1 that are consistent with our previous subsection (i.e., a steady-state measure of product lines equal to 0.58 and 0.72 in islands 1 and 2, respectively). Figure 4 shows that the steady-state output share in islands 1,2 , and 3 is equal to $0.17,0.29$, and 0.54 , respectively. While island 3 is still only $10.5 \%$ more productive than island 1 (as in the case without entry-exit), island 3's output is now 209\% larger than island 2's output, instead of $82 \%$ as without entry-exit. Equation (8) tells us why. Due to its higher productivity, island 3 searches more actively, attracts more vendors and accumulates more product lines. As $\pi_{j}^{I}$ gets close to one, this mechanism becomes arbitrarily large. That is, entry-exit generates an even stronger "Matthew effect." 


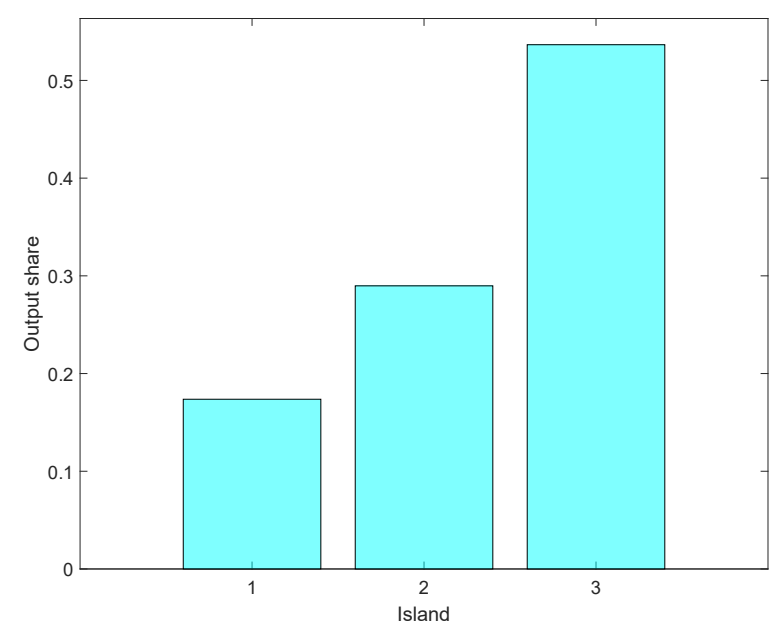

Figure 4: Output share across islands

But market concentration also depends on the cost of signing a vendor contract. For example, imagine that due to the enhancements in search technology (e.g., better logistics software), it becomes cheaper for firm $F$ to send buying agents to each island. Technically, we let the unit cost of visiting each island, $\kappa$, decrease at a constant one-percent rate per period (i.e., $\left.\kappa_{t}=0.99^{t-1} \cdot \phi / 2\right)$.
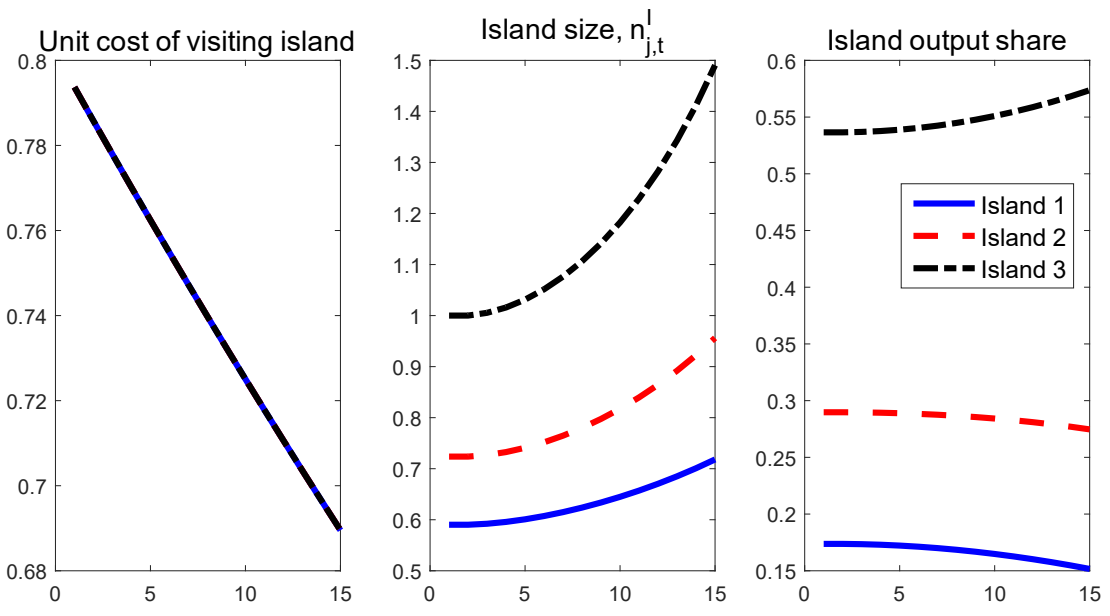

Figure 5: Reduction in search costs

Figure 5 plots the unit cost of visiting each island (left panel), the measure of productive lines for firm $I$ (central panel), and the final output share (right panel) for each island. The decline in unit search cost attracts more buying agents from firm $F$ to all islands and, thus, increases the probability of forming a vendor relation and the number of active product lines $\left(n_{j, t}^{I}\right.$, middle panel). While all three islands have more active product lines, search complementarities make 
the increase in $n_{j, t}^{I}$ proportional to each island's productivity. Therefore, island 3 benefits the most from the decline in $\kappa$ and the output shares of islands 1 and 2 fall over time. In comparison, in the model without entry and exit, the output in all three islands grows at the same rate, and market concentration remains unchanged. That is, we need both search complementarities and entry-exit to transform reductions in search cost into changes in market concentration.

Our result is consistent with the finding in Aghion et al. (2019), who show that the increasing share of output for high productivity firms is mostly accounted for by a decreasing cost of expanding new businesses. Consider the following example. Historically, each Whole Foods store sourced its products with independent local suppliers (or "local foragers"). Following the Amazon-Whole Foods merger, Amazon took advantage of its leadership in logistics software to revamp the existing Whole Foods vendor contract arrangements and started prioritizing contracts with national, higher-productivity suppliers at the expense of local foragers.
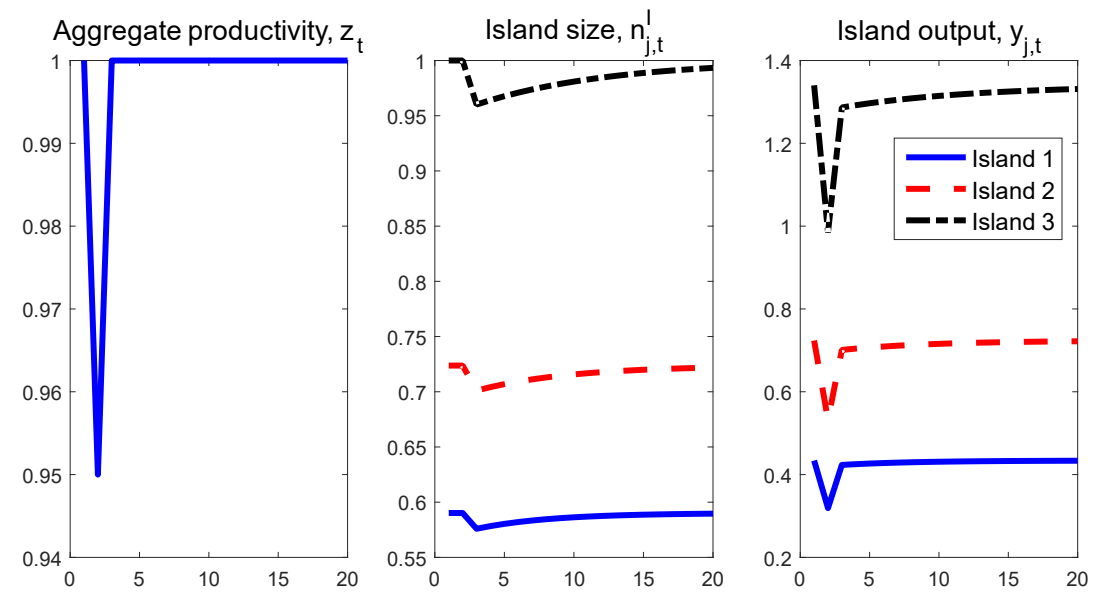

Figure 6: IRFs to negative aggregate productivity shock

Figure 6 shows the IRFs of the measure $n_{j, t}^{I}$ and output $y_{j, t}$ in the three islands (right panel) to a one-period decrease in aggregate productivity $\left(z_{t}\right)$ from 1 to 0.95 (left panel). Output (aggregate and in each island) falls by $26 \%$, as in the case without entry and exit: both versions of the model behave in the same way at impact. The difference with respect to Figure 3 is that now, through entry and exit, we have i) persistence of the output fall (even if the productivity shock only lasts for one period) and that ii) such persistence is asymmetric across islands. In period 10, output is still $0.55 \%$ below its initial level in island 1, $0.95 \%$ in island 2, and $1.72 \%$ is island 3 . In this version of our simple model, negative productivity shocks lower firm concentration. 


\subsection{Monopsony power of the labor market}

Our final step in this Section is to show how search complementarity interacts with monopsony power in the labor market. ${ }^{3}$ In particular, we will show five additional results: i) monopsony power lowers wages ceteris paribus; ii) wages grow with the productivity of the firm; iii) monopsony power reduces the marginal effect of the firm's productivity on wages; iv) monopsony power strengths the "Matthew effect" of productivity differences even further and increases wage inequality; v) reductions in the cost of signing a vendor contract lower labor income share, but redistributes labor toward higher productivity jobs.

Before we can discuss the role of monopsony power in the labor market, we need to specify labor supply and demand. To keep the model as transparent as possible, we assume that right after the vendor-relation formation, a measure $u_{t}$ of workers from the representative household are randomly matched to active product lines. The labor match lasts for one period and separates at the end of each period. The measure of labor market meeting is determined by the Leontief function:

$$
M_{t}=\min \left(u_{t}, \sum_{j} \pi_{j, t}^{I} n_{j, t}^{I}\right),
$$

where $\sum_{j} \pi_{j, t}^{I} n_{j, t}^{I}$ is the total measure of active product lines.

For simplicity, we assume that $u_{t}=\sum_{j} \pi_{j, t}^{I} n_{j, t}^{I}$, so the meeting probability is equal to one for both sides of the match. ${ }^{4}$ A worker's probability of meeting with an active product line in island $j$ is $s_{j, t}=\pi_{j, t}^{I} n_{j, t}^{I} / \sum \pi_{k, t}^{I} n_{k, t}^{I}$, the share of active product lines in island $j$.

The wage in island $j, w_{j, t}$, is determined by Nash bargaining between the worker and an active product line. If the worker rejects the wage offer, she becomes unemployed in this period and the active product line receives a zero profit.

To introduce monopsony power of the labor market, we assume that active product lines in the same island negotiate wages in a collective way: if a worker rejects an offer from an active product line in island $j$, all other active product lines in island $j$ would "punish" the worker by refusing to match with her with probability $\lambda$ in the next period. ${ }^{5}$ Then, if a worker declines a

\footnotetext{
${ }^{3}$ Berger et al. (2019), Hershbein et al. (2020), and Manning (2020), among others, have shown evidence regarding the effect of monopsony power in the labor market and market concentration.

${ }^{4}$ This assumption eliminates the need to keep track of the percentage of workers or product lines not matched. We can justify the number of workers being a function of the active product lines with the representative household's preferences without wealth effects.

${ }^{5}$ For simplicity, we assume that firms have exogenous commitment to this negotiation rule.
} 
wage offer from an active product line, she forgoes $w_{j, t}+\lambda s_{j, t+1} \cdot w_{j, t+1}$, the lost wage today plus the probability of losing a wage tomorrow, which is proportional to the island's labor market share, $s_{j, t+1}$. Firms will optimally take advantage of this forgone income to increase their profits.

To see this, notice that the total surplus of a labor market match is $\operatorname{LT} S_{j, t}=\left(2 z_{t} x_{j}-w_{j, t}\right)+$ $\left(w_{j, t}+\lambda s_{j, t+1} w_{j, t+1}\right)$, where $\left(2 z_{t} x_{j}-w_{j, t}\right)$ and $\left(w_{j, t}+s_{j, t+1} \cdot w_{j, t+1}\right)$ are the surplus of the active product line and the worker's payoff from the labor market match, respectively (here we implicitly assume linear preferences on income for the worker). Nash bargaining implies that $2 z_{t} x_{j}-w_{j, t}=\tau \cdot L T S_{j, t}$ and $w_{j, t}+\lambda s_{j, t+1} \cdot w_{j, t+1}=(1-\tau) L T S_{j, t}$, where $\tau$ and $(1-\tau)$ are the bargaining shares of the active product line and the worker, respectively.

Suppose, first, that labor market punishment is forbidden, i.e., $\lambda=0$. In this case, the wage, $w_{j}^{*}=(1-\tau) 2 z_{t} x_{j}$, is a fraction $1-\tau$ of output. The derivative of the wage with respect to the island productivity $x_{j}$ is $(1-\tau) 2 z_{t}$.

When $\lambda>0$, we have instead:

$$
w_{j}=\frac{(1-\tau) 2 z_{t} x_{j}}{1+\tau \lambda s_{j}}=\frac{1}{1+\tau \lambda s_{j}} w_{j}^{*}<w_{j}^{*} .
$$

where we can see the monopsony wedge $\frac{1}{1+\tau \lambda s_{j}}<1$.

From this expression, we have:

$$
\frac{d w_{j}}{d x_{j}}=\frac{(1-\tau) 2 z_{t}}{1+\tau \lambda s_{j}}-\frac{\tau \lambda}{\left(1+\tau \lambda s_{j}\right)^{2}} \frac{\partial s_{j}}{\partial x_{j}}<(1-\tau) 2 .
$$

since higher productivity islands have more active product lines everything else equal $\left(\frac{\partial s_{j}}{\partial x_{j}}>1\right)$.

Equations (10) and (11) teach us three lessons. First, the monopsony wedge lowers the island's wage $i$ with respect to the case without monopsony power. Second, $w_{j}$ increases with the island's productivity, but decreases with the island's active product lines share. The latter change is a general equilibrium effect: the island's share depends on its productivity but also on the productivity of all the other firms in the economy. That is, if firms in other islands are more productive, they will decrease the number of workers in the current island and, therefore, suppress search efforts and wages. Third, wages grow more slowly than productivity in the firms' cross-section.

Figure 7 illustrates these three lessons by plotting the distribution of wage in the steady 
state of the economy $\left(z_{t}=z=1\right)$ with no monopsony power $(\lambda=0)$ and with monopsony power $(\lambda=0.1)$. Since we calibrate $\tau=0.5$, we have $(1-\tau) 2 z_{t}=1$. To make our exercise comparable with the previous subsections, we reset $x_{1}=1.9, x_{2}=2$, and $x_{3}=2.1$. Then, when labor market punishment is forbidden, firms' profits and the Nash equilibrium are then same as in Subsection 2.3.

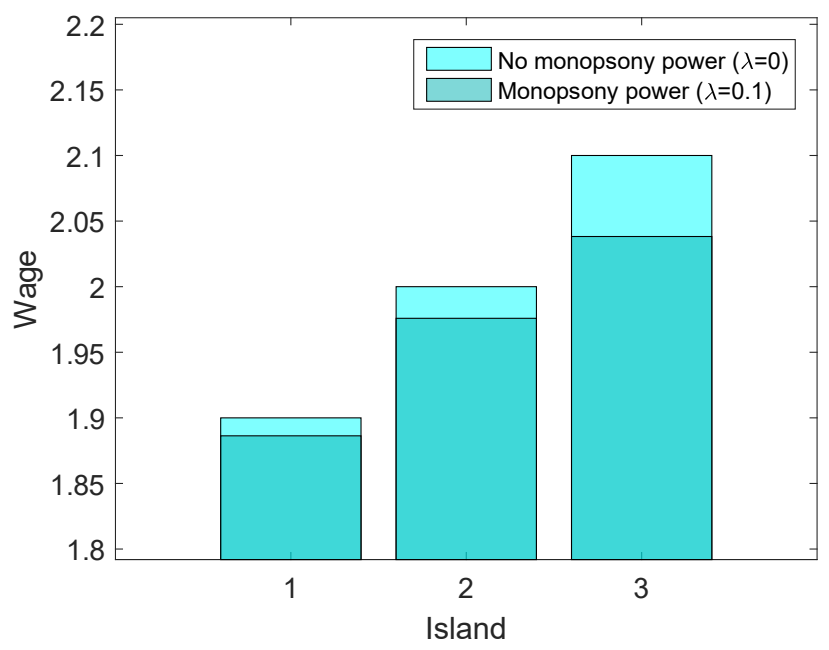

Figure 7: Wage with different $\lambda$

Figure 7 shows how, when $\lambda=0$, wages grow one-to-one with productivity: $w_{1}=1.9$, $w_{2}=2$, and $w_{3}=2.1$. However, under monopsony power, wages i) are lower, ii) and grow more slowly than productivity: $w_{1}=1.89, w_{2}=1.98$, and $w_{3}=2.04$. The wedge between wages and productivity is increasing in the island's output share.

We move now to analyze the effects of monopsony power on market concentration. As before, we assume that firm $F$ and firm $I$ evenly split their joint surplus $\left(2 z_{t} x_{j}-w_{j, t}\right)$. Equations (4) and (5) become:

$$
\sigma_{j, t}^{I}=\sqrt{\phi\left(z_{t} x_{j}-w_{j, t} / 2\right) \widehat{n}_{j}^{F}}
$$

and

$$
\widehat{n}_{j, t}^{F}=\phi \sigma_{j, t}^{I}\left(z_{t} x_{j}-w_{j, t} / 2\right)
$$

We just saw that, with monopsony power, firms pay a lower wage and achieve a higher profit. This higher profit provides firms a higher incentive to search. Figure 8 documents this result by plotting the steady-state output share for each island. In the left panel, we plot the distribution of output shares when $\lambda=0$, which is the same as in Figure 4 . In the right panel, we plot the 

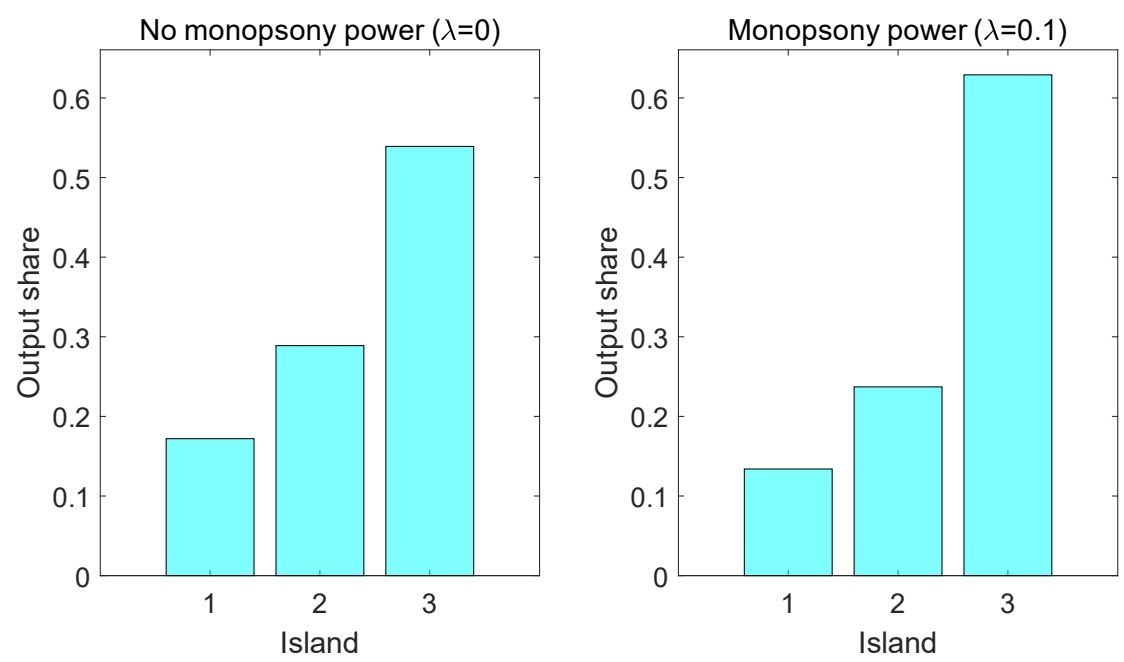

Figure 8: Output share with different $\lambda$

distribution of output shares when $\lambda=0.1$. The incremental incentive of search is highest for island 3 as it has the greatest effective labor market power due to its size, and is lowest for island 1. As a result, labor market power makes the market structure more concentrated. Island 3's share of output grows from 0.54 to 0.62 and island's 2 share falls from 0.17 to 0.14 .

This additional strengthening of the "Matthew effect" stands in contrast with the results from a classic model of monopsony in the labor market. In such a classic model, monopsony leads to a smaller firm, since the monopsonist wants to equate marginal revenue product of labor to the marginal cost of labor by reducing labor hired. In our model, the monopsonist wants to hire more workers, because larger size allows it to keep more of the total surplus.

Another way to think about this mechanism is that a higher $\lambda$ leads to a lower labor income share: firms that keep a larger share of the labor surplus grow more in size. When $\lambda=0$, the labor income share is 0.5 (the Nash bargaining parameter). When $\lambda=0.1$, the labor income share is 0.49. But, although the share of labor income is lower, the total labor income is $33 \%$ higher. Labor income share falls because, when $\lambda=0.1$, we are providing the incentives for higher productivity firms to scale up and relocate more workers from the low-wage jobs in islands 1 and 2 to the highest-wage jobs in island 3.

We should be careful mapping our results to findings from cross-sectional regression of wages on labor market power such as those reported in Marinescu et al. (2020). In our model, all firms have the same monopsony power. Thus, our model's predictions are about two economies with different monopsony power in the labor market (e.g., the U.S. vs. France), not about two 
firms within the same economy. To think about the latter case, we would need to consider some dimension along which firms diverge, possibly by producing a differentiated good.

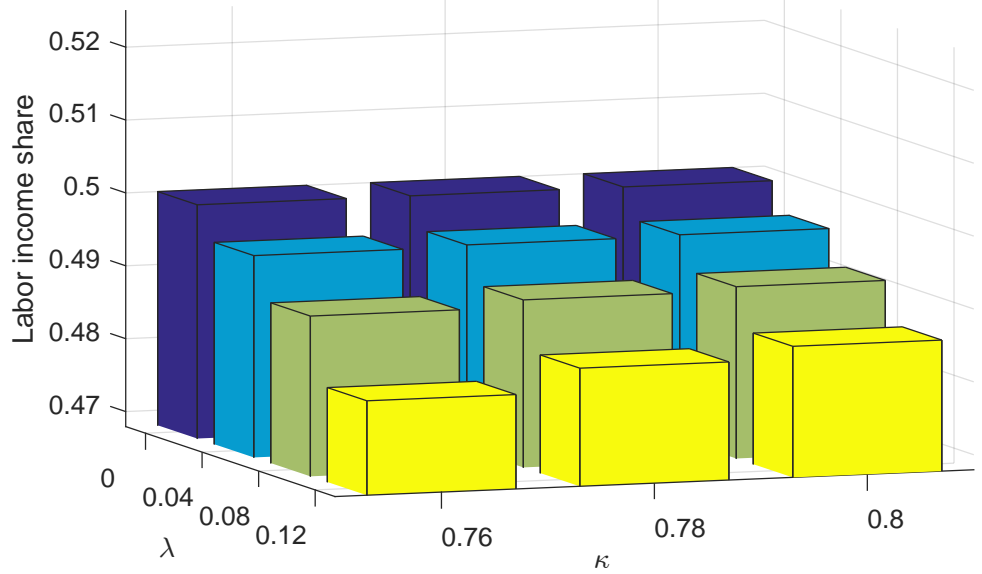

Figure 9: Labor income share with different $\lambda$

Figure 9 displays the aggregate labor income share for different values of $\kappa$ and $\lambda$. As we move over the $\lambda$-axis, we see the labor share reduction that we described above. But, interestingly, Figure 9 shows that our model has another mechanism to account for the recent reduction of the labor share in the U.S. economy: a fall in $\kappa$. Since a fall in the cost of signing vendor-contract relations leads to higher market concentration, it will also lead to firms' higher market power. As we move over the $\kappa$-axis, the labor income share falls but output and productivity increases.

Thus, our model predicts that changes such as better software and other technologies to manage vendors and suppliers deliver i) more market concentration and ii) lower labor income share but also iii) higher average wages and iv) higher productivity. More pointedly, our model also suggests that the differences observed between the U.S. and Europe over the last decades in terms of market concentration, labor income shares, and wage and productivity growth ${ }^{6}$ may be due to differences in the speed of adopting information technologies that allow for a cheaper scale-up of businesses on each side of the Atlantic. Also, European labor market regulations might limit the extent to which European firms can exert their monopsony power in the labor market, limiting their ability to scale up production.

Figure 10, which displays the wage distribution for different values of $\kappa$ and $\lambda$, documents these effects. In each plot, the vertical top-circled line presents workers' density for each wage, and the vertical discontinuous line, the average wage. Either a higher $\lambda$ or a lower $\kappa$ make the

\footnotetext{
${ }^{6}$ See, for some empirical documentation of these differences, Cette et al. (2019), and Covarrubias et al. (2019).
} 
market structure more concentrated and, therefore, allocate more workers to more productive firms (i.e., an increase in the height of the vertical line at the right). However, $\lambda$ and $\kappa$ have different effects on the level of wages. A higher $\lambda$ generally decreases the wage for every worker (i.e., shifts all the vertical lines to the left). In contrast, a lower $\kappa$ reduces the highest wage but increases the medium and the lowest wages. On the other hand, a higher $\lambda$ also increases wage inequality: more workers move to higher-wage jobs.
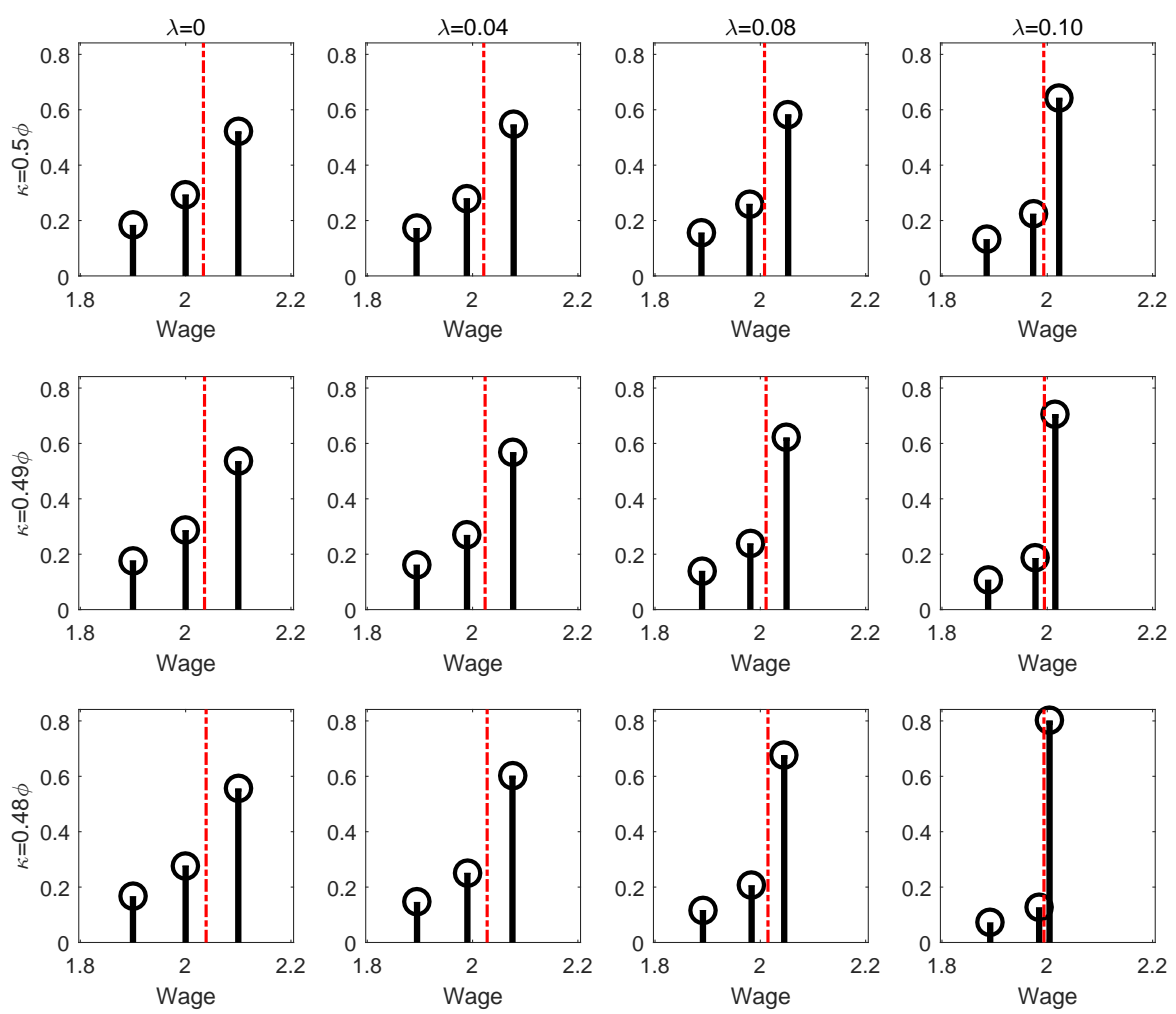

Figure 10: Wage distribution with different $\lambda$

We finish this subsection with Figure 11, the analogous to Figure 6 but with monopsony power. Aggregate output falls $27 \%$ at impact and, as before, the IRFs show persistence. As in Figure 6, island 3 is the one that experiences the largest output over time. Notice, however, that our simple model ignores an important factor of wage bargaining. The stronger market power of high productivity firms can increase low-productivity firms' employees' outside option value by making it easier to find high-paying jobs, which lowers the low-productivity firms' profit margin. In the extended model, we will see how this missing factor can make low-productivity firms more responsive to productivity shocks. 

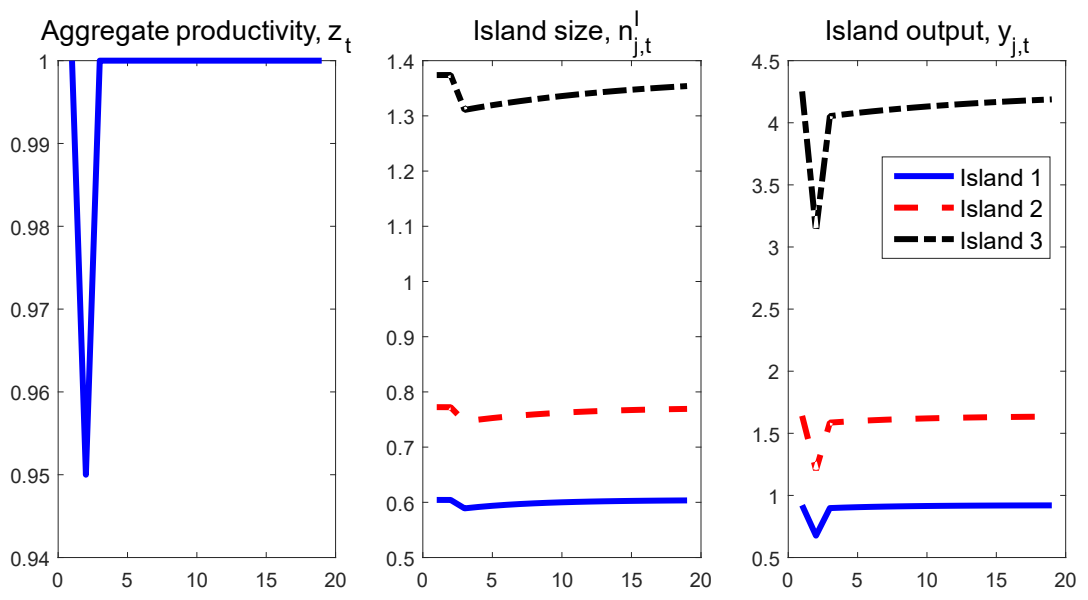

Figure 11: IRFs to negative aggregate productivity shock

\subsection{Taking stock}

We can now summarize the eight main takeaways from our simple model:

1. Search complementarities, under directed search, result in a "Matthew effect" that transforms small differences in productivity into large output differences. This effect appears in the cross-section (among different firms) and the time-series (for temporary aggregate productivity shocks).

2. Entry and exit make the "Matthew effect" even more prominent.

3. Entry and exit make the degree of market concentration depend on the cost of signing a vendor contract. This observation gives us a theory of why market concentration has been growing in the U.S. economy over time: the fall in search costs related to business relations.

4. Monopsony power in the labor market strengthens the "Matthew effect" across firms further. In our model, search complementarities imply that firms want to get bigger and hire more workers to keep more of the surplus. This result stands in stark contrast with the classic monopsony model, in which firms want to reduce the amount of labor they hire, which leads to relatively smaller firms.

5. Monopsony power lowers wages for a given level of productivity, and such a percentage of reduction grows with the firm size. 
6. Higher monopsony power increases wage inequality by redistributing workers to higher market firms, which are also higher productivity firms.

7. Reductions in the cost of signing a vendor contract lower the labor income share, but shifts workers' distribution toward high-wage jobs.

8. With entry and exit and monopsony power, aggregate productivity shocks change market concentration, generating a long persistence of the effects of short-lived aggregate shocks.

Let us analyze how these takeaways appear in our extended, quantitative model.

\section{$3 \quad$ Extended model}

In this section, we extend our simple model along several important dimensions. First, we broaden the analysis to a general equilibrium framework by including utility-maximizing households that choose consumption and labor supply and allowing for a richer heterogeneity in intermediate goods producers. Second, we introduce persistence in vendor relations. Third, we flesh out the monopsony power in the labor market to be consistent with the granular search theory in Jarosch et al. (2019).

\subsection{The representative household}

The economy is populated by a continuum of households of size one. Each household has preferences represented by:

$$
\mathbb{E}_{0} \sum_{t=0}^{\infty} \beta^{t}\left[\log \left(C_{t}\right)+\xi\left(1-h_{t}\right)\right],
$$

where $\mathbb{E}_{0}$ is the conditional expectations operator at time $0, \beta \in(0,1)$ is the discount factor, $\xi \geq 0$ is the marginal disutility of labor, $C_{t}$ is consumption of final goods, and $h_{t}$ is total hours worked in the household (defined below). The time constraint is normalized to one. Total hours worked is equal to $h_{t}=\sum_{j} \widehat{n}_{j, t} h_{j, t}$, where $\widehat{n}_{j, t}$ represents the fraction of households working in $j$-type product line. The household's budget constraint is $C_{t}=\sum_{j} n_{j, t} w_{j, t} h_{j, t}+\Pi_{t}$, where $w_{j, t}$ and $h_{j, t}$ are the wage rate and the labor supply in $j$-type product line, respectively. $\Pi_{t}$ is the per-capita profit from ownership of firms. The wage is different across product lines for the presence of search and matching frictions. 


\subsection{The labor market and the goods market: an overview}

There are $j=1,2, \ldots, J$ types of firms in the intermediate-goods sector $I$, and each $j$-type firm manufactures identical intermediate goods using a technology with different productivity. We denote the idiosyncratic productivity for firm $I$ of type $j$ as $x_{j}$. Without loss of generality, we assume strictly increasing idiosyncratic productivity in the index of firm type (i.e., $x_{1}<$ $\left.x_{2}<\ldots<x_{J}\right)$. Each firm $I$ manages a positive measure of product lines, which we interpret as firm size. The distribution of firms size is endogenously determined by search-matching and entry-exit processes, as we describe below. A law of large numbers holds in this economy, equating individual probabilities with realized shares.

To manufacture goods, a product line must first form a vendor relationship with a final goods producer (firm $F$ ) and match with a worker. Firms in the final-goods sector $F$ have the same productivity. Each firm sends buying agents to form vendor relationships with product lines that supply intermediate goods to them. Search is directed, and each firm in sector $F$ optimally chooses the $j$-type firm in sector $I$ to visit. Since $J$ types of firm $I$ exist, there are $J$ segmented inter-firm sub-markets, indexed by $j$. Sending a buying agent to submarket $j$ incurs

the unit $\operatorname{cost} \kappa$. Each firm $I$ in submarket $j$ chooses the costly search effort, denoted by $\sigma_{j, t}^{I}$, to maximize the expected profits. Variable search effort and directed search generate strategic complementarities since the degree of optimal search effort exerted by firm $I$ is increasing in the measure of buying agents sent by firm $F$. Similarly, the optimal measure of buying agents sent by firm $F$ also will be increasing in the search effort exerted by firm $I$.

After forming a vendor relation, each vendor relation without a worker posts one vacancy (without any costs) in the labor market and stays idle. At the end of each period, vendor relations and labor market matches separate exogenously with probability $\widehat{\delta}$ and $\delta$, respectively, and in either case, workers become unemployed.

Figure 12 summarizes the timeline for firm $I$. At the beginning of each period, product lines search for buying agents to establish a vendor relation. Next, vendor relations search for workers. If successfully matched with a worker, the vendor relation enters the production stage; otherwise it stays idle. Vendor relations and labor market matches separate randomly at the end of each period. 


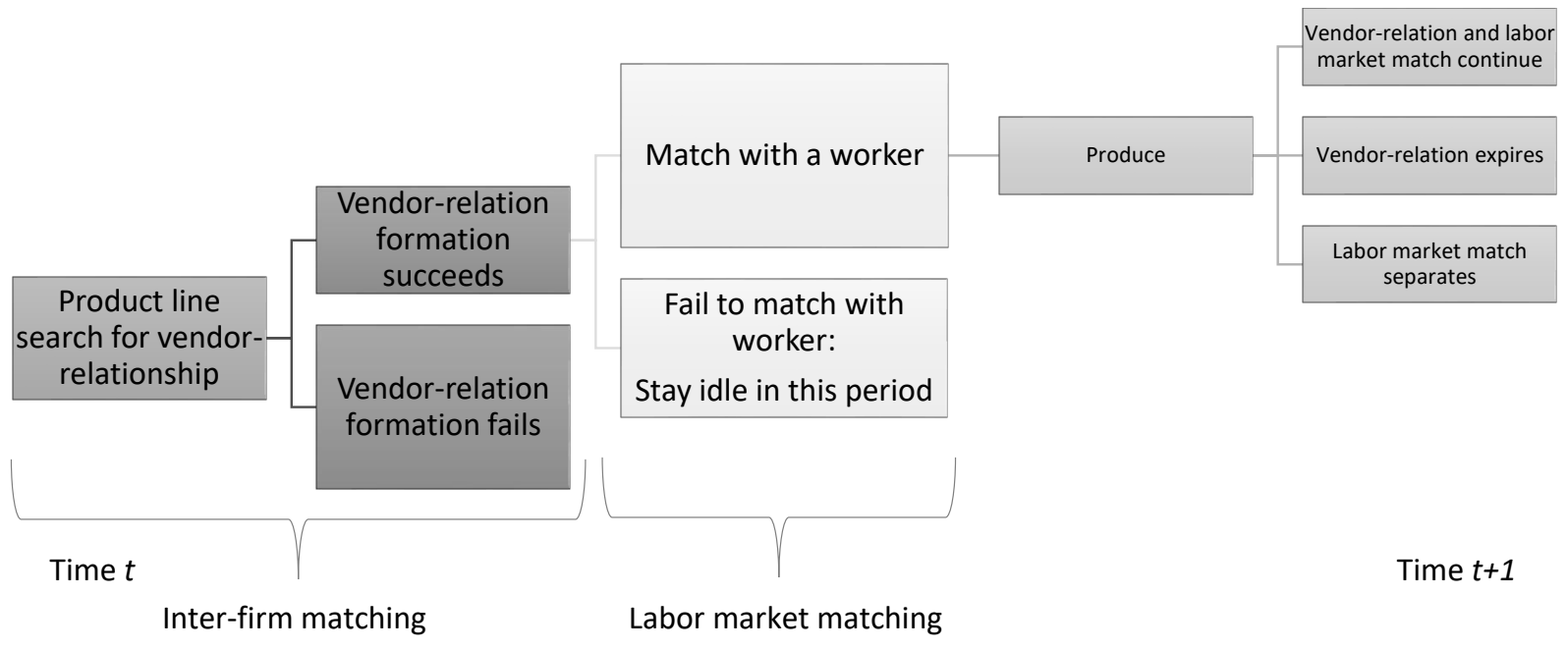

Figure 12: Timeline for firm $I$.

\subsection{The labor market: search frictions and monopsony power}

\subsubsection{Matching function}

We assume a frictional labor market. We depart from the DMP framework by allowing multiple workers to apply to a single vacancy randomly. With this simple variation with respect to the standard model, we give firms monopsony power in the labor market because they can threaten to preclude workers who decline a wage offer from future job offers. Therefore, the bargained wage may be below the marginal product of labor.

The matching technology is formulated by the process of randomly placing balls in urns as in Butters (1977). Product lines play the role of urns and workers the role of balls. An urn becomes "productive" when it has a ball in it. Even with exactly the same number of urns and balls, a random placing of the balls in the urns will not match all the pairs exactly because of a coordination failure by those placing the balls in the urns. Some urns will end up with more than one ball and some with none. In the context of the labor market, if only one worker could occupy each job, an uncoordinated application process by workers will lead to overcrowding in some jobs and to no applications in others. As illustrated by Petrongolo and Pissarides (2001), the imperfection that leads to unemployment in this environment is the lack of information about other workers' action.

In the simplest version of this process, we assume that workers and vendor relations are discrete. There are $u_{t}$ number of unemployed workers who know the location of $v_{t}$ number of 
unmatched product lines. If a product line receives one or more job applications, it selects one applicant and forms a match (the selection criterion is specified below), while the other applicants become unemployed in the current period $t$.

Given that each product line receives a worker's application with probability $1 / \widetilde{n}_{t}$, and there are $u_{t}$ applicants, with probability $\left(1-1 / v_{t}\right)^{u_{t}}$ a given product line will receive no applications. Thus, the number of labor market matches formed in each period is:

$$
E_{t}=v_{t}\left[1-\left(1-1 / v_{t}\right)^{u_{t}}\right]
$$

We let the measure of each product line and worker be infinitely small, such that $\widetilde{n}_{t}$ and $u_{t}$ tends to infinity, in which case we have that $\lim _{v_{t}, u_{t} \rightarrow \infty} E_{t}=v_{t}\left(1-e^{v_{t} / u_{t}}\right)$. Then, the vacancy filling rate is:

$$
p_{t}^{n}=\frac{E_{t}}{v_{t}}=1-e^{-u_{t} / v_{t}}
$$

and the job finding rate is:

$$
p_{t}^{u}=\frac{E_{t}}{u_{t}}=v_{t} / u_{t} \cdot\left(1-e^{-u_{t} / v_{t}}\right) .
$$

To introduce labor market power, we adopt a "granular search" approach proposed by Jarosch et al. (2019), who show that large firms hold a strong bargaining power by threatening workers with future job refusals since workers can hardly avoid large employers and they are likely to re-apply to job-openings from the same firms in the future. We denote the measure of vendor relations managed by the type- $j$ firms that are not matched with a worker as $v_{j, t}$, which we interpret as a proxy for the size of the labor market. Thus, the number of unmatched product lines is $v_{t}=\sum_{j=1}^{J} v_{j, t}$. We define the relative labor market size, $s_{j, t}$, as the fraction of unfilled product lines owned by type- $j$ firms with $s_{j, t}=v_{j, t} / v_{t}$ and $\sum_{j=1}^{J} s_{j, t}=1$, which is endogenously determined. In general, a more productive firm and a firm that searches more actively gain a higher $s_{j, t}$ that generates stronger labor market power.

The dynamics in the model depend on the three important probability functions. First, since meetings between workers and job openings are i.i.d. across workers, the conditional probability $p^{n}$ that a worker meeting a product line is not the only applicant to the job opening. Second, the probability $s \cdot p^{u}$ that a worker meets with a product line owned by a large firm (that possesses the fraction $s$ of matched product lines of the economy). Lastly, the probability that a worker 
contacts a product line owned by the same firm and that the product line has more than one job applicant: $s \cdot p^{u} \cdot p^{n}$.

Labor market matches separate exogenously with probability $\delta$. In addition, if a product line becomes obsolete (with probability $\widehat{\delta}$ ), the labor market match terminates.

\subsubsection{Monopsony power and value functions}

The wage is determined by Nash bargaining. The bargaining set is within the output of the product line $y_{j, t}$ and the disutility of working $\xi h_{j, t}$. When multiple homogeneous workers apply to a single vacancy, the product line offers a wage contract to one candidate. The product line exerts its monopsony power by threatening the worker to forgo future hiring if the current offer is rejected. This threat is particularly powerful when the product line belongs to a firm of large size since job applicants are likely to re-encounter the same firm in the future with a probability proportional to relative labor market size $\left(s_{j}\right)$. Thus, more productive (and therefore larger) firms retain a stronger threatening power.

The firm that operates the product line precludes workers who reject a current job offer from future hiring with probability $\widetilde{\delta}$, such that the expected duration of the punishment is $1 / \widetilde{\delta}$ periods. To rule out the complicated case of everlasting punishments and the possibility that a worker is punished by multiple firms, we assume that firms withdraw punishment to workers once hired by other production lines.

We now define the Bellman equations that determine the value of an unemployed worker without punishment $U_{t}$, of an unemployed worker punished by type- $j$ firm $\widetilde{U}_{j, t}$, of an employed worker in a type- $j$ firm $W_{j, t}$, of a product line owned by type- $j$ firm that is matched with a worker $J_{j, t}$, and of a product line that is not matched with a worker $X_{j, t}$.

The value of an unemployed worker without punishment is:

$$
U_{t}=\xi+\mathbb{E}_{t}\left\{\beta\left(\frac{C_{t}}{C_{t+1}}\right)\left[p_{t}^{u} \sum_{k} s_{k, t} W_{k, t+1}+\left(1-p_{t}^{u}\right) U_{t+1}\right]\right\},
$$

where $\xi$ is the flow of utility from being unemployed at period $t$. In the next period $t+1$, the worker finds a job in a $k$-type product line with probability $p_{t}^{u} \cdot s_{k, t}$ and becomes employed, or $\mathrm{s} /$ he remains unemployed with probability $1-p_{t}^{u}$. The continuation value is discounted by the stochastic discount factor, $\beta\left(C_{t} / C_{t+1}\right)$. 
The value of an unemployed worker under punishment by type- $j$ firm is:

$$
\begin{aligned}
& \widetilde{U}_{j, t}=\widetilde{\delta} U_{j, t} \\
& +(1-\widetilde{\delta})\left\{\xi+\mathbb{E}_{t}\left[\beta\left(\frac{C_{t}}{C_{t+1}}\right)\left\{\begin{array}{c}
p_{t}^{u}\left[\sum_{k \neq j} s_{k, t} W_{k, t+1}+s_{j, t}\left(1-p_{t}^{n}\right) W_{j, t+1}\right] \\
+\left(1-p_{t}^{u}+p_{t}^{u} s_{j, t} p_{t}^{n}\right) \widetilde{U}_{j, t+1}
\end{array}\right\}\right]\right\},
\end{aligned}
$$

where with probability $\widetilde{\delta}$, the punishment to the worker is forgiven and the value of unemployment becomes $U_{j, t}$. Otherwise, the worker is under punishment. The first two terms in the first row in the second curly bracket show that the worker finds a job in a type- $k$ product line $(k \neq j)$ with probability $p_{t}^{u} \cdot s_{k, t}$ that brings value $W_{k, t+1}$, and with probability $p_{t}^{u} \cdot s_{j, t}$, the worker's job application reaches type- $j$ product line, and the worker is hired either if the firm is not the one that enforces punishment, or if the firm that enforces punishment has no other applications, which occurs with probability $1-p_{t}^{n}$. The term in the second row represents the expected value of remaining unemployed in the next period $t+1$, either because the worker fails to meet any vacancy (with probability $1-p_{t}^{u}$ ) or because the worker meets a type- $j$ product line, but the product line has alternative applicants (with probability $p_{t}^{u} s_{j, t} p_{t}^{n}$ ) and, thus, rejects the worker.

By multiplying equation $(15)$ by $(1-\widetilde{\delta})$ and subtracting equation (16) from it, we obtain the loss of value associated with labor market punishment:

$$
U_{t}-\widetilde{U}_{j, t}=(1-\widetilde{\delta}) \mathbb{E}_{t}\left\{\beta\left(\frac{C_{t}}{C_{t+1}}\right)\left[\begin{array}{c}
s_{j, t} p_{t}^{u} p_{t}^{n}\left(W_{j, t+1}-U_{t+1}\right) \\
+\left(1-p_{t}^{u}+s_{j, t} p_{t}^{u} p_{t}^{n}\right)\left(U_{t+1}-\widetilde{U}_{j, t+1}\right)
\end{array}\right]\right\}
$$

In the deterministic steady state, equation (17) reduces to:

$$
U-\widetilde{U}_{j}=\frac{(1-\widetilde{\delta}) \beta s_{j} p^{u} p^{n}\left(W_{j}-U\right)}{1-\beta\left(1-p^{u}+s_{j} p^{u} p^{n}\right)(1-\widetilde{\delta})}
$$

Equation (18) shows that if $\widetilde{\delta}=1$, there is no labor market punishment and $U=\widetilde{U}_{j}$. If $\widetilde{\delta}<1$, however, equation (16) implies that $U>\widetilde{U}_{j}$, that is, labor market punishment generates a loss to the worker since s/he prefers working to being unemployed (i.e., $W_{j}>U$ ). Moreover, equation (18) shows that the loss of value due to labor market punishment strictly increases with the firm's relative labor market size $\left(s_{j}\right)$, and strictly decreases with the probability of 
forgiving $(\widetilde{\delta})$. When the firm's labor market size is zero, we have $U=\widetilde{U}_{j}$.

The value of an employed worker in a vendor-relation is:

$$
W_{j, t}=w_{j, t}+\mathbb{E}_{t}\left\{\beta\left(\frac{C_{t}}{C_{t+1}}\right)\left[(1-\delta-\widehat{\delta}) W_{j, t+1}+(\delta+\widehat{\delta}) U_{t+1}\right]\right\}
$$

where the first term on the right-hand-side (RHS) of equation (19) is the current period wage $w_{j, t}$ to be determined by Nash bargaining. The job relationship terminates randomly either because the job separates with probability $\delta$ or the vendor-relation dissolves with probability $\widehat{\delta}$ and in both instances the worker becomes unemployed and gains value $U_{t+1}$. Otherwise, the worker continues the job relation and earns value $W_{j, t+1}$.

Similarly, the value of firms in a vendor-relation with a worker is:

$$
J_{j, t}^{k}=\Pi_{j, t}^{k}+\mathbb{E}_{t}\left\{\beta\left(\frac{C_{t}}{C_{t+1}}\right)\left[(1-\delta-\widehat{\delta}) J_{j, t+1}^{k}+\delta X_{j, t+1}^{k}+\widehat{\delta} \widetilde{J}_{j, t+1}^{k}\right]\right\}, k \in\{I, F\}
$$

where the first term on the RHS of equation (20) is current profit, and the second term is the continuation value in the next period $t+1$, in which the job separates with probability $\delta$ and the idle vendor-relation gets $X_{j, t+1}^{k}$ (defined below), or the vendor-relation dissolves with probability $\widetilde{\delta}$ and each firm gets $\widetilde{J}_{t+1}^{k}$.

The value of an idle product line without a worker is:

$$
X_{j, t}^{k}=\mathbb{E}_{t}\left\{\beta\left(\frac{C_{t}}{C_{t+1}}\right)\left[p_{t}^{n} J_{j, t+1}^{k}+\left(1-p_{t}^{n}\right) X_{j, t+1}^{k}\right]\right\}, k \in\{I, F\} .
$$

Equation (21) shows that an idle product line produces zero profits in period $t$, but by hiring a worker with probability $p_{t}^{n}$ it receives the value $J_{j, t+1}^{k}$. Otherwise, with probability $\left(1-p_{t}^{n}\right)$, the product line remains unmatched and earning $X_{j, t+1}^{k}$ in the next period $t+1$.

The value of a product line without a vendor-relation is:

$$
\widetilde{J}_{j, t}^{I}=-c\left(\sigma_{j, t}\right)+\mathbb{E}_{t}\left\{\beta\left(\frac{C_{t}}{C_{t+1}}\right)\left[\pi_{j, t}^{I} X_{j, t+1}^{I}+\left(1-\pi_{j, t}^{I}\right)(1-\chi) \widetilde{J}_{j, t+1}^{I}\right]\right\} .
$$

Equation (22) shows that a product line without a vendor relation exerts search effort in period $t$, and in the next period $t+1$, finds a firm in sector $I$ with probability $\pi_{j, t}^{I}$ that yields a value $X_{j, t+1}^{I}$. Otherwise, if it survives obsolesce with probability $(1-\chi)$, it remains without a vendor 
relation and yields a value of $\widetilde{J}_{j, t+1}^{I}$.

Lastly, when a vendor-relation terminates, the buying agent of firm $F$ returns to the central island and receives zero value:

$$
\widetilde{J}_{j, t}^{F}=0
$$

Firms in the intermediate and final-goods producers, $I$ and $F$, split the joint-profit from the match by Nash bargaining, which yields:

$$
\frac{X_{j, t}^{I}-\widetilde{J}_{j, t}^{I}}{\tau}=\frac{X_{j, t}^{F}-\widetilde{J}_{j, t}^{F}}{1-\tau}
$$

where $X_{j, t}^{k}-\widetilde{J}_{j, t}^{k}$ is the capital gain by signing a vendor-contract. The parameter $\tau$ is the bargaining share of firm $I$.

\subsubsection{Wage determination}

The wage is negotiated between the worker and the vendor-relation by Nash bargaining. The total surplus from forming match in the labor market $\left(L T S_{j, t}\right)$ is equal to:

$$
L T S_{j, t}=\left(J_{j, t}-X_{j, t}\right)+\left(W_{j, t}-\widetilde{U}_{j, t}\right)
$$

where $J_{j, t}$ and $X_{j, t}$ are joint-values of vendor-relation with $J_{j, t}=J_{j, t}^{I}+J_{j, t}^{F}$, and $X_{j, t}=X_{j, t}^{I}+X_{j, t}^{F}$. Equation (25) departs from the standard bargaining protocols because the worker surplus

depends on $\widetilde{U}_{j, t}$ rather than $U_{t}$, and the additional surplus $\left(U_{t}-\widetilde{U}_{j, t}\right)$ arises from the firm's credible threat of future rejection.

Thus, the bargained wage $\left(w_{j, t}\right)$ satisfies:

$$
W_{j, t}-\widetilde{U}_{j, t}=(1-\widetilde{\tau}) L T S_{j, t}
$$

and

$$
J_{j, t}-X_{j, t}=\widetilde{\tau} L T S_{j, t}
$$

where $\widetilde{\tau}$ is the vendor-relation's bargaining share.

In the online appendix, we prove the following proposition. 
Proposition 1. In the steady state, ceteris paribus, the wage decreases with the firm's vacancy share $\left(s_{j}\right)$ and increases with the probability of forgiveness $(\widetilde{\delta})$.

Proposition 1 shows that, conditional on a level of productivity, a greater market power - either because a firm represents a larger share in the labor market or because a firm has a lower probability of forgiveness- implies a lower wage.

\subsection{The goods market: vendor contract formation}

As in the simple model, the matching process in each submarket is governed by a technology with variable search intensity. Following Burdett and Mortensen (1980), the number of newly formed vendor relations in market $j$ is:

$$
M\left(\widetilde{n}_{j, t}^{F}, \widetilde{n}_{j, t}^{I}, \sigma_{j, t}^{I}\right)=\psi \sigma_{j, t}^{I} H\left(\widetilde{n}_{j, t}^{F}, \widetilde{n}_{j, t}^{I}\right)
$$

where $\sigma_{j, t}^{I}$ is the firm $I$ 's variable search effort, $\widetilde{n}_{j, t}^{F}$ is the measure of firm $F$ 's buying agents, and $\widetilde{n}_{j, t}^{I}$ is the measure of product lines owned by type- $j$ firm $I$. The parameter $\psi$ controls the efficiency in matching. The function $H(\cdot)$ has constant returns to scale and it is strictly increasing in both arguments.

Each submarket $j$ has a tightness ratio $\theta_{j, t}$, defined as $\theta_{j, t}=n_{j, t}^{F} / n_{j, t}^{I}$. The probability that a product line forms a joint venture with a firm in sector $F$ is:

$$
\pi_{j, t}^{I}=\frac{M\left(\widetilde{n}_{j, t}^{F}, \widetilde{n}_{j, t}^{I}, \sigma_{j, t}^{I}\right)}{\widetilde{n}_{j, t}^{I}}=\psi \sigma_{j, t}^{I} \mu\left(\theta_{j, t}\right)
$$

and the probability that a firm in sector $F$ forms a vendor relation with firm-type $j$ in sector $I$ is:

$$
\pi_{j, t}^{F}=\frac{M\left(\widetilde{n}_{j, t}^{F}, \widetilde{n}_{j, t}^{I}, \sigma_{j, t}^{I}\right)}{\widetilde{n}_{j, t}^{F}}=\psi \sigma_{j, t}^{I} q\left(\theta_{j, t}\right),
$$

where $\mu\left(\theta_{j, t}\right)=H\left(\theta_{j, t}, 1\right)$ and $q\left(\theta_{j, t}\right)=H\left(1,1 / \theta_{j, t}\right)$. Then, $\mu^{\prime}\left(\theta_{j, t}\right)>0$ and $q^{\prime}\left(\theta_{j, t}\right)<0$.

Each firm in sector $I$ faces the cost of searching with intensity $\sigma_{j, t}^{I}$ equal to:

$$
c\left(\sigma_{j, t}^{I}\right)=\frac{\left(\sigma_{j, t}^{I}\right)^{1+\nu}}{1+\nu}, \quad j \in\{1,2, \ldots, J\}
$$




\subsubsection{Production technology}

A product line manufactures intermediate goods according to the production technology:

$$
\widetilde{y}_{j, t}=x_{j} h_{j, t}
$$

where $\widetilde{y}_{j, t}$ is the output for firms in the intermediate-goods sector (a tilde indicates intermediategoods sector variables), and $x_{j}$ is the idiosyncratic productivity for type- $j$ intermediate goods producer. Each product line matches with one worker and hours are fixed to one (i.e., $h_{j, t}=1$ ).

Final goods producers transform the intermediate goods into the final goods $y_{j, t}$ with the linear production technology:

$$
y_{j, t}=z_{t} \widetilde{y}_{j, t}=z_{t} x_{j}
$$

where the aggregate productivity $z_{t}$ follows $\log \left(z_{t}\right)=\rho_{z} \log \left(z_{t-1}\right)+\sigma_{z} \epsilon_{t}$, where $\epsilon_{t} \sim \mathcal{N}(0,1)$.

Total output is split among the worker, the product line, and the final goods producer, such that $w_{j, t}+\Pi_{j, t}^{I}+\Pi_{j, t}^{F}=y_{j, t}$, where $W_{j, t}, \Pi_{j, t}^{I}$, and $\Pi_{j, t}^{F}$ are the wage of the worker, profits of the product line and final goods producer (conditional on vendor relation formation and labor market matching), respectively, which are determined by Nash bargaining.

\subsubsection{Optimal search effort for intermediate goods producers}

The product line chooses the optimal search effort by maximizing the value $\widetilde{J}_{j, t}$ :

$$
\max _{\sigma_{j, t}^{I} \geq 0}-c\left(\sigma_{j, t}\right)+\mathbb{E}_{t}\left\{\beta\left(\frac{C_{t}}{C_{t+1}}\right)\left[\pi_{j, t}^{I} X_{j, t+1}^{I}+\left(1-\pi_{j, t}^{I}\right)(1-\chi) \widetilde{J}_{j, t+1}^{I}\right]\right\},
$$

where $\pi_{j, t}^{I}$ is the probability of vendor relation formation. $J_{j, t}(0)$ and $J_{j, t}(1)$ are the ex-post value of product line defined in equation (20) that are conditional on success and failure of vendor contract, respectively. The interior solution to the maximization problem in equation (30) is:

$$
\left(\sigma_{j, t}^{I}\right)^{\nu}=\mathbb{E}_{t}\left[\beta\left(\frac{C_{t}}{C_{t+1}}\right) \psi \mu\left(\theta_{j, t}\right) \Delta J_{j, t+1}^{I}\right],
$$

where $\Delta J_{j, t}$ is the capital gain due to the establishment of a vendor contract:

$$
\Delta J_{j, t+1}=X_{j, t+1}^{I}-(1-\chi) \widetilde{J}_{j, t+1}^{I},
$$


which includes the capital gain $X_{j, t+1}^{I}-\widetilde{J}_{j, t+1}^{I}$, and the gain $\chi \widetilde{J}_{j, t+1}^{I}$ that captures the fact that product line with a vendor contract does not become obsolete.

The left-hand side (LHS) of equation (31) is the marginal cost of exerting search effort to form a vendor relation for $j$-type firm in sector $I$, and the RHS of the equation is the expected benefit of signing a vendor contract, which increases in tightness $\theta_{j, t}\left(\right.$ since $\left.\mu^{\prime}\left(\theta_{j, t}\right)>0\right)$ and in the capital gain from forming a vendor relation.

The solution to the optimization problem is:

$$
\sigma_{j, t}^{I}=\left\{\mathbb{E}_{t}\left[\beta\left(\frac{C_{t}}{C_{t+1}}\right) \psi \mu\left(\theta_{j, t}\right) \Delta J_{j, t+1}^{I}\right]\right\}^{\frac{1}{\nu}}
$$

Since $\nu>1$ and $\mu(\cdot)$ is an increasing function, equation (33) shows that the optimal search intensity $\sigma_{j, t}^{I}$ increases with the tightness ratio $\theta_{j, t}$, implying that $\sigma_{j, t}^{I}>0$.

In the online appendix, we show the following result.

Proposition 2. In the steady state, ceteris paribus, firm I's search effort increases with the firm's vacancy share $s_{j}$, and it decreases with the probability of forgiveness $\widetilde{\delta}$.

Proposition 2 establishes that strong market power -either because a firm owns a larger share in the labor market, or because it exercises a lower probability of forgiveness- implies a greater search effort (conditional on a level of productivity and number of visiting from sector $F)$. Intuitively, a strong labor market power enables firms to offer a lower wage to the worker, which expands the firm's profit for every signed vendor contract, which in turn stimulates an active search. As we will show later, a critical implication of Proposition 2 is that labor market power entails a more concentrated market structure.

\subsubsection{Buying agents and search complementarity}

The expected value of sending a buying agent for a firm in sector $F$ is:

$$
V_{t}^{F}=\max _{j}\left\{-\kappa+\mathbb{E}_{t}\left[\beta\left(\frac{C_{t}}{C_{t+1}}\right) \pi_{j, t}^{F}\left(X_{j, t+1}^{F}-\widetilde{J}_{j, t+1}^{F}\right)\right]\right\} .
$$

Equation (34) shows that each firm in sector $F$ pays a unit cost $\kappa$ for each agent who visits submarket $j$ that may establish a vendor relation with probability $\pi_{j, t}^{F}=\psi \sigma_{j, t}^{I} q\left(\theta_{j, t}\right)$, and brings a capital gain $X_{j, t+1}^{F}-\widetilde{J}_{j, t+1}^{F}$. 
Firms in sector $F$ send buying agents to visit prospective intermediate goods suppliers at the optimal submarkets until the value of forming a vendor relation collapses to zero (recall that a law of large numbers hold in the economy and thus, conditional on the aggregate states, expected and realized profits are equated): $V_{t}^{F}=0$.

Substituting this last condition into equation (34), we get:

$$
\max _{j}\left\{-\kappa+\mathbb{E}_{t}\left[\beta\left(\frac{C_{t}}{C_{t+1}}\right) \psi \sigma_{j, t}^{I} q\left(\theta_{j, t}\right)\left(X_{j, t+1}^{F}-\widetilde{J}_{j, t+1}^{F}\right)\right]\right\}=0
$$

such that the expected capital gain in each submarket $j$ is equal to the cost $\kappa$ :

$$
q\left(\theta_{j, t}\right) \sigma_{j, t}^{I} \mathbb{E}_{t}\left[\beta\left(\frac{C_{t}}{C_{t+1}}\right) \psi \cdot\left(X_{j, t+1}^{F}-\widetilde{J}_{j, t+1}^{F}\right)\right]=\kappa
$$

and consequently the submarkets with a higher capital gain, $X_{j, t+1}^{F}-\widetilde{J}_{j, t+1}^{F}$, attracts more buying agents to visit. The inflow of buying agents increases the tightness ratio in each submarket, which decreases the matching probability for those buying agents. In equilibrium, the tightness ratio adjusts to make the expected gain from entering into all submarkets equal to the cost $\kappa$.

Equation (35) implies that, because $q(\cdot)$ is a decreasing function, the tightness ratio $\theta_{j, t}$ increases with intermediate goods producers' search effort $\sigma_{j, t}^{I}$ :

$$
\theta_{j, t}=q^{-1}\left[\frac{\kappa}{\sigma_{j, t}^{I} \mathbb{E}_{t}\left[\beta\left(\frac{C_{t}}{C_{t+1}}\right) \psi \cdot\left(X_{j, t+1}^{F}-\widetilde{J}_{j, t+1}^{F}\right)\right]}\right] .
$$

As in our simple model, directed search is key to generate search complementarity in the formation of vendor relations.

\subsection{Period equilibrium}

Given the aggregate state of the economy, the period equilibrium of submarket $j$ is a tuple of $\left\{\sigma_{j, t}^{I}, \theta_{j, t}\right\}$ that is a fixed point of the product of the best response function (33) and the optimality condition (36). As before, we ignore the trivial equilibrium with zero output. The whole dynamic equilibrium of the economy is a repetition of these period equilibria as linked by the value functions outlined above.

To determine the measure of firms and aggregate output, we assume that new product lines 
are created at the constant rate $n$ in each period $t$. The measure of product lines that remain unmatched with final goods producer in the next period $t+1\left(\widetilde{n}_{j, t+1}^{I}\right)$ is equal to those lines that fail to sign a vendor-contract and do not become obsolete $\left(\left(1-\pi_{j, t}^{I}\right)(1-\chi) \widetilde{n}_{j, t}^{I}\right)$, plus those that recently separate from vendor-relation $\left(\widehat{\delta} n_{j, t}^{I}\right)$, and the new product line $(n)$, such that:

$$
\widetilde{n}_{j, t+1}^{I}=\left(1-\pi_{j, t}^{I}\right)(1-\chi) \widetilde{n}_{j, t}^{I}+\widehat{\delta} n_{j, t}+n
$$

Using the definition of the tightness ratio $\theta_{j, t}$, the measure of buying agents sent to submarket $j$ is $\widetilde{n}_{j, t}^{F}=\widetilde{n}_{j, t}^{I} \theta_{j, t}$, and the measure of vendor-relation $\left(n_{j, t+1}\right)$ comprises those that survive vendor-relation separation $\left((1-\widehat{\delta}) n_{j, t}\right)$ plus new vendor-relation formation $\left(\pi_{j, t}^{I} \widetilde{n}_{j, t}^{I}\right)$, such that:

$$
n_{j, t+1}=(1-\widehat{\delta}) n_{j, t}+\pi_{j, t}^{I} \widetilde{n}_{j, t}^{I}
$$

The measure of vendor relations matched with a worker $\left(\widehat{n}_{j, t+1}\right)$ comprises those that do not separate with worker and do not dissolve $\left((1-\delta-\widehat{\delta}) \widehat{n}_{j, t}\right)$ plus the new labor market matches $\left(p_{t}^{n} v_{j, t}\right)$ :

$$
\widehat{n}_{j, t+1}=(1-\delta-\widehat{\delta}) \widehat{n}_{j, t}+p_{t}^{n} v_{j, t}
$$

The measure of vendor relations that are unmatched with workers is $v_{j, t}=n_{j, t}-\widehat{n}_{j, t}$, and the measure of vacancies corresponds to the total measure of vendor relations that are unmatched with workers $v_{t}=\sum v_{j, t}$.

Unemployment is equal to $u_{t+1}=\left(1-p_{t}^{u}\right) u_{t}+(\delta+\widehat{\delta}) \sum \widehat{n}_{j, t}$, where the first term on the RHS shows the unemployment outflow induced by job creation $\left(p_{t}^{u} u_{t}\right)$, and the second term shows the unemployment inflow from random job and vendor-relation separation.

Aggregate output is a weighted sum of final goods produced across submarkets $Y_{t}=$ $\sum_{j=1}^{J} \widehat{n}_{j, t} y_{j, t}$, where $\widehat{n}_{j, t}$ is the measure of vendor relations matched with worker, determined by equation (39), and $y_{j, t}$ is the final output of vendor relations, determined by equations (28) and (29), respectively. Aggregate output is used for aggregate consumption, $C_{t}$, search costs, and entry costs, which yields:

$$
Y_{t}=C_{t}+\sum_{j=1}^{J} \widetilde{n}_{j, t}^{I} \frac{\left(\sigma_{j, t}^{I}\right)^{1+\nu}}{1+\nu}+\kappa \sum_{j=1}^{J} \widetilde{n}_{j, t}^{F}
$$




\section{Calibration and measurement}

We calibrate our model by matching its deterministic steady state (DSS) to post-WWII U.S. data at a quarterly frequency. A discount factor $\beta$ of 0.987 (equivalent to 0.95 at a yearly frequency) replicates an average annual interest rate of $5 \%$ over the sample period.

We pick 20 productivity types, $J$, such that each type of firm $I$ corresponds to a vigintile of the productivity-distribution. Hence, type- 1 firms are the bottom $5 \%$ of the productivity distribution and type-20 firms the top 5\%. In our model, the measured total-factor productivity (mTFP) of firms $I$ results from the combination of the exogenous productivity, $x_{j}$, and the endogenous product line utilization rate, $n_{j} /\left(n_{j}+\widetilde{n}_{j}^{I}\right)$. Thus, we calibrate the dispersion of $x_{j}$ to match the observations by Syverson (2011) that the average ratio of mTFP between industry plants' at the 90th and 10th percentile of the productivity distribution using four-digit SIC industries in the U.S. manufacturing sector is 1.92. We match this ratio by assuming that $\log \left(x_{j}\right)$ is uniformly distributed between -0.12 and 0.12 .

With respect to the search cost function, we set $\nu=3$, implying that the marginal search cost is a quadratic function of the search effort. We normalize the cost of signing a vendor-contract to be equal to the average productivity of vendor relations, i.e., $\kappa=1$ (the parameter $\psi$, to be calibrated below, varies to compensate for this normalization).

We calibrate $\widehat{\delta}=1 / 16$ to replicate the average duration of 4 years in vendor relations in the Compustat Customer Segment data (which report the major customers for a subset of U.S. listed companies on a yearly basis). For the $H(\cdot)$ function, we assume a Cobb-Douglas form,

$\psi\left(\widetilde{n}_{j}^{F}\right)^{\alpha}\left(\widetilde{n}_{j}^{I}\right)^{1-\alpha}$, where $\alpha=0.5$ imposes symmetry. By setting $\psi=0.54$, we get that $88 \%$ of product lines for the medium firms are active in the DSS, matching the observed $12 \%$ average rate of idleness in the U.S. non-manufacturing and manufacturing sectors before the Great Recession (Michaillat and Saez, 2015, and Ghassibe and Zanetti, 2020).

Following Shimer (2005) and Thomas and Zanetti (2009), the flow value of unemployment $\xi$ (the marginal value of leisure in our model) is set to $40 \%$ of the mean labor productivity. The worker's bargaining share $\widetilde{\tau}$ is set to 0.65 , such that the labor income share of output is equal to 0.66, consistent with the long-run average of labor share in the U.S. economy. With $\tau=0.5$, the remaining $34 \%$ of total income is evenly distributed between firms $I$ and $F$.

We normalize population to one. Following Shimer (2005), we target the quarterly job finding 
rate $p^{u}=0.7$, an unemployment rate, $u=0.055$, and labor market tightness $v / u=1.3$. These targets imply that the probability of filling a vacancy, equal for all firms, is $p^{n}=\left(1-e^{v / u}\right)=0.54$, the employment-to-unemployment $(\mathrm{EU})$ transition rate is $0.041(0.041 /(0.041+0.7)=0.055)$, and the EU transition probability from vendor-contract dissolutions is $\left(1-p^{u}\right) \widehat{\delta}=0.019$. Thus $\delta$, the exogenous job separation rate, is $0.041-0.019=0.022$. We set the creation rate of new product lines, $\widehat{n}$, equal to 0.0017 to be consistent with this calibration.

In our model, the rate of obsolescence of a product line can be interpreted as the rate of plant exit. Lee and Mukoyama (2015) estimate the average exit rate of manufacturing plants equal to $5.5 \%$ on a yearly basis (1.4\% on a quarterly basis) using Longitudinal Research Database (LRD) from the U.S. Census Bureau (see Hamano and Zanetti, 2017, for a discussion on the empirical estimates of plant entry and exit rates). Hence, we set the rate of product line obsolescence $\chi=0.13$ and get an average obsolete rate equal to $1.4 \%$.

Finally, we use the model to measure the probability of labor market forgiveness, $\widetilde{\delta}$, equal to 0.51, that matches the output share of top $10 \%$ firms of 0.64 reported by Autor et al. (2020). A value $\widetilde{\delta}=0.51$ means that firms forgive workers on average after 2 periods (i.e., after six months). In our numerical analysis below, we will vary $\widetilde{\delta}$ to assess the non-linear effect of monopsony power on market concentration. Table 1 summarizes our model's calibration.

\begin{tabular}{lcc}
\hline Description & Parameter & Value \\
\hline Discount factor & $\beta$ & 0.987 \\
Number of firm type & $J$ & 20 \\
Productivity & $\log \left(x_{j}\right)$ & $\mathcal{U}[-0.12,0.12]$ \\
Search cost function, curvature & $\nu$ & 3 \\
Cost of sending a buying agent & $\kappa$ & 1 \\
Vendor contract expiration rate & $\widehat{\delta}$ & $1 / 16$ \\
Matching elasticity & $\alpha$ & 0.5 \\
Matching efficiency & $\psi$ & 0.54 \\
Flow value of unemployment & $\xi$ & 0.4 \\
Worker's bargaining share & $\widetilde{\tau}$ & 0.65 \\
Final goods firm's bargaining share & $\tau$ & 0.5 \\
Exogenous job separation rate & $\delta$ & 0.022 \\
Inflow of product line & $\widehat{n}$ & 0.0017 \\
Rate of product line obsolescence & $\chi$ & 0.14 \\
Probability of labor market forgiveness & $\widetilde{\delta}$ & 0.51 \\
\hline
\end{tabular}

Table 1: Calibration 


\section{Quantitative results}

In this section, we report the main quantitative findings from our extended model:

1. Search effort is increasing with the level of productivity.

2. Search complementarities, in the presence of direct search, induce market concentration in terms of firms' size, vacancies, and output.

3. Monopsony power in the labor market reinforces the role of search complementarities: high-productivity firms get bigger. Monopsony power lowers wages and the labor income share, but it also moves workers toward high-wage jobs and increases wage inequality.

4. Monopsony power in the labor market, in the absence of strategic complementarities, has a limited effect on market concentration.

5. Lower search costs increase market concentration.

6. Search complementarities amplify the effect of negative aggregate productivity shocks and make them much more persistent. Negative aggregate productivity shocks also increase market concentration because they disproportionally affect the output of low-productivity firms and lower the volatility of the economy in response to negative aggregate shocks.

Notice how these findings mirror our simple model's main takeaways in Section 2. Let us review each of these quantitative findings in more detail.

\subsection{Search effort is increasing with the level of productivity}

Figure 13 plots, for each productivity level $(j)$, the search efforts $\left(\left\{\sigma_{j}^{I}\right\}_{j=1}^{J}\right.$, top panel) of firms $I$, the measure of buying agents sent by firm $F$ to each island $\left(\left\{\tilde{n}_{j}^{F}\right\}_{j=1}^{J}\right.$, middle panel), and the probability for product-lines to form vendor relations $\left(\left\{\pi_{j}^{I}\right\}_{j=1}^{J}\right.$, bottom panel), all at the DSS. Higher productivity intermediate-goods producers search more intensively, attract more buying agents, and enjoy a higher matching probability. 


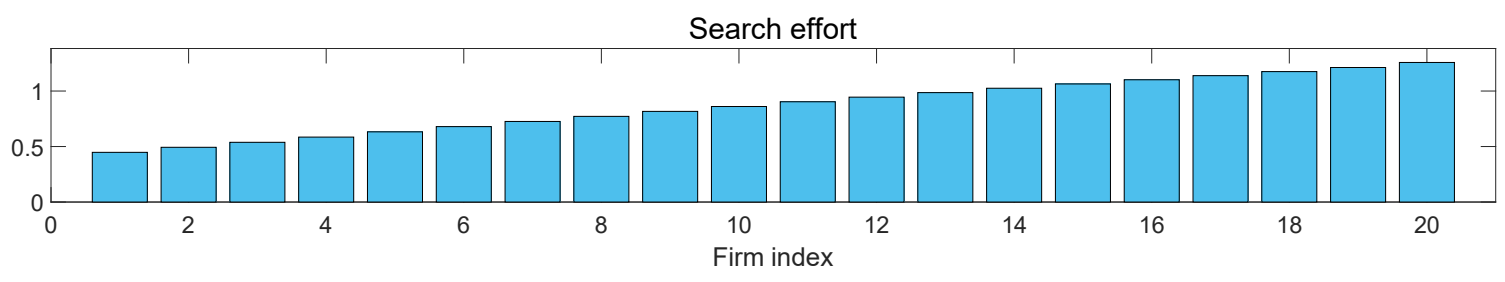

Measure of buying agents

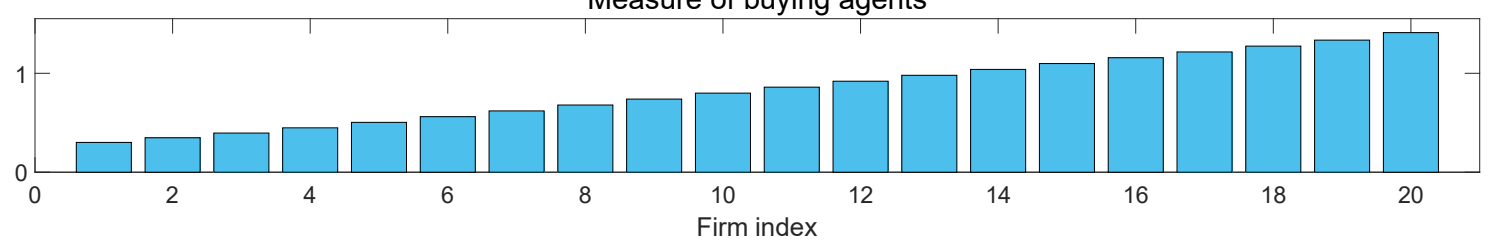

Matching probability

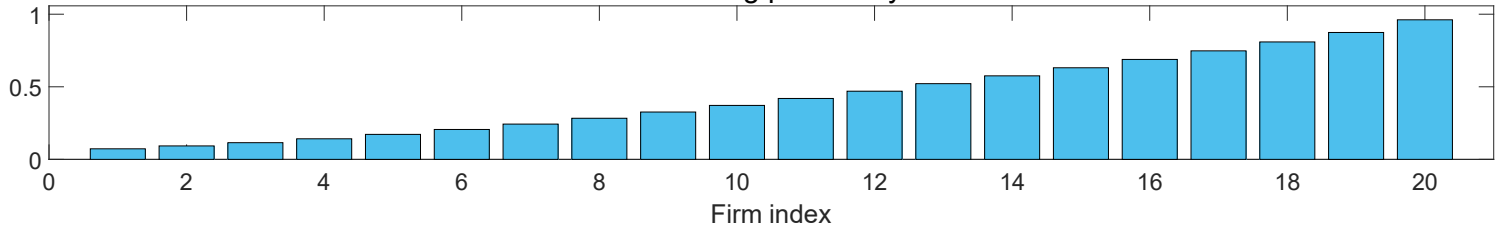

Figure 13: Search effort at the DSS

\subsection{Search complementarities induce market concentration}

We turn now to the distribution of firm size (i.e., measure of product lines), vacancies, and output. Equations (37) and (38) give us the measures of production lines that are unmatched:

$$
\widetilde{n}_{j}^{I}=\frac{n}{\left(1-\pi_{j, t}^{I}\right) \chi}
$$

and matched in the DSS:

$$
n_{j}=\frac{n \pi_{j, t}^{I}}{\widehat{\delta}\left(1-\pi_{j, t}^{I}\right) \chi} .
$$

Therefore, firm size is:

$$
n_{j}+\widetilde{n}_{j}^{I}=\frac{n\left(1+\pi_{j}^{I} / \widehat{\delta}\right)}{\left(1-\pi_{j}^{I}\right) \chi},
$$

which is strictly increasing in the probability of vendor relation formation $\pi_{j}^{I}$, and strictly decreasing in the rate of product line obsolescence $\chi$.

The upper panel of Figure 14 plots the distribution of the measure of product lines matched with a worker. The measure of product lines is increasing in the firm's productivity and highly concentrated among the "superstar firms": the top 5\% own $48 \%$ of product lines at the DSS and the next $5 \%$ owns an additional $14.5 \%$. 

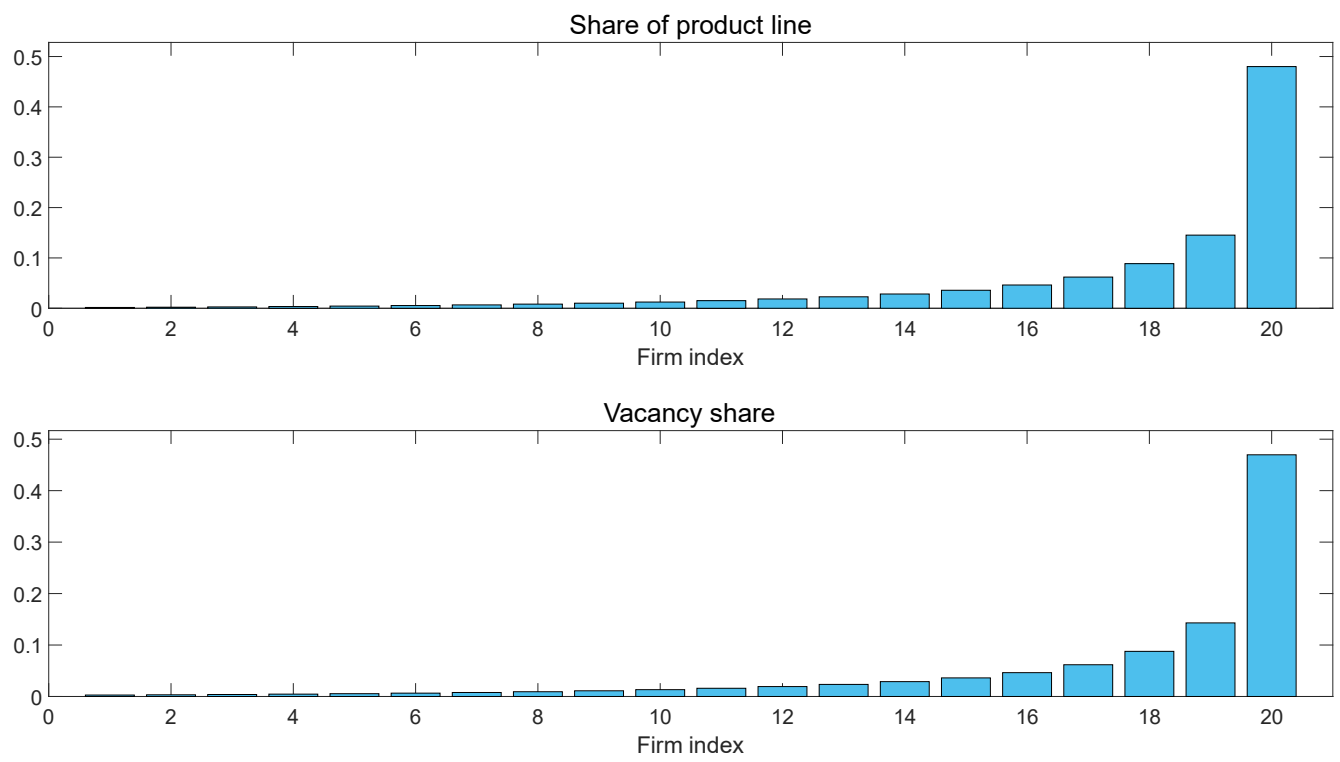

Figure 14: Firm size and vacancies at the DSS

The high concentration of product lines appears despite a moderate productivity dispersion in our calibration. The top 5\% firms own around three times as many product lines as the next $5 \%$ of firms, although the former ones are only $1.3 \%$ more productive than the latter. Why do we have such large differences? Because equations (40)-(41) imply that the measure of product lines is nonlinear in $\pi_{j}^{I}$. As shown in the bottom panel of Figure 13, the nonlinearity becomes stronger when the measure gets close to one, which is the case for the most productive firms.

With respect to the distribution of vacancies (bottom panel of Figure 14), since all firms $I$ have the same vacancy-filling rates, vacancies are a measure of effective labor demand. The number of vacancies posted by the firm of $j$-type productivity:

$$
v_{j}=\frac{n_{j}}{1+p^{n} /(\delta+\widehat{\delta})}=\frac{(\delta+\widehat{\delta}) n \pi_{j}^{I}}{\widehat{\delta}\left(1-\pi_{j}^{I}\right) \chi\left(p^{n}+\delta+\widehat{\delta}\right)} .
$$

is strictly increasing in the probability of forming a vendor relation $\pi_{j}^{I}$, but strictly decreasing in the rate of product line obsolescence $\chi$, for a given probability of matching with a worker $p^{n}$. Intuitively, a higher $\pi_{j}^{I}$ or a lower $\chi$ decreases the rate of product line obsolescence and, hence, raise the DSS measure of product lines $\left(n_{j}+\widetilde{n}_{j}^{I}\right)$. As a firm gains more product lines, it also has a greater need to expand hiring $\left(v_{j}\right)$ to staff a larger production. For instance, at the DSS, the top $5 \%$ of firms post $47 \%$ of all vacancies and the next $5 \%, 14.3 \%$. 
With respect to the distribution of output, type- $j$ firm produces, at the DSS:

$$
y_{j}=\underbrace{z x_{j}}_{\text {Output per active product line }} \cdot \underbrace{\frac{n_{j}}{n_{j}+\widetilde{n}_{j}^{I}}}_{\text {prod. line util. rate }} \cdot \underbrace{n_{j}+\widetilde{n}_{j}^{I}}_{\text {Measure of prod. line }} \cdot \underbrace{\frac{\widehat{n}_{j}}{n_{j}}}_{\text {labor market matching }}
$$

Equation (42) embodies the four complementary channels that generate market concentration in our model. First, high-productivity firms produce larger output per active product line (the first term in the RHS of equation (42)). While this channel is present in most models with heterogeneous firms, in our model it explains only a small fraction of industry concentration given the small calibrated productivity dispersion. Second, high-productivity firms search more actively for potential partners, and, due to directed search and search complementarities, potential partners send more buying agents to them. Consequently, high-productivity firms have a higher product line utilization rate (the second term in the RHS of equation (42)). Third, since the product lines of high-productivity are active more frequently, fewer of them become obsolete, which leads to an increase in the measure of high-productivity product lines (the third term in the RHS of equation (42)). Four, firms have monopsony power (i.e., $\widetilde{\delta}<1$ ). This monopsony power increases the profit share of vendor matches and provides incentives to intermediate goods producers to exert a higher search effort and expand their active product lines. By gaining market share, high-productivity firms can extract a larger share of the labor surplus. This effect, however, is somewhat hidden in equation (42) because it affects $\widetilde{n}_{j}^{I}$ and $n_{j}^{I}$ nonlinearly. Thus, we will return to these nonlinear relations in the next subsection.

Like channels two and three, channel four is a novel and powerful mechanism to generate market concentration. The key point is that the effect of monopsony power in the labor market is not uniform across firms. Its effect is minimal for low-productivity firms, since their labor market power is limited due to their small labor market size. However, labor market punishment increases the output share of high-productivity firms $\left(s_{j}\right)$, which in turn increases labor market power. In other words, market concentration and monopsony power reinforce each other.

Figure 15 displays the quantitative implication of these channels. The top panel shows the distribution of the rate of utilization of product lines at the DSS. High-productivity firms form vendor relations more quickly and, thus, utilize their product lines more efficiently. While the bottom $5 \%$ of firms have $54 \%$ of their product lines active, the top $5 \%$ operate $95 \%$ of their 
product lines. The bottom panel shows the distribution of $I$-firms' output share $\left(y_{j} / Y\right)$. The most productive firms account for a disproportionate share of output: the top 5\% produce $49 \%$ of output and the next $5 \%$ produce an additional $15 \%$, while the bottom $5 \%$ only generate $0.13 \%$ of output. These numbers are in line with the empirical observations documented by Autor et al. (2020).
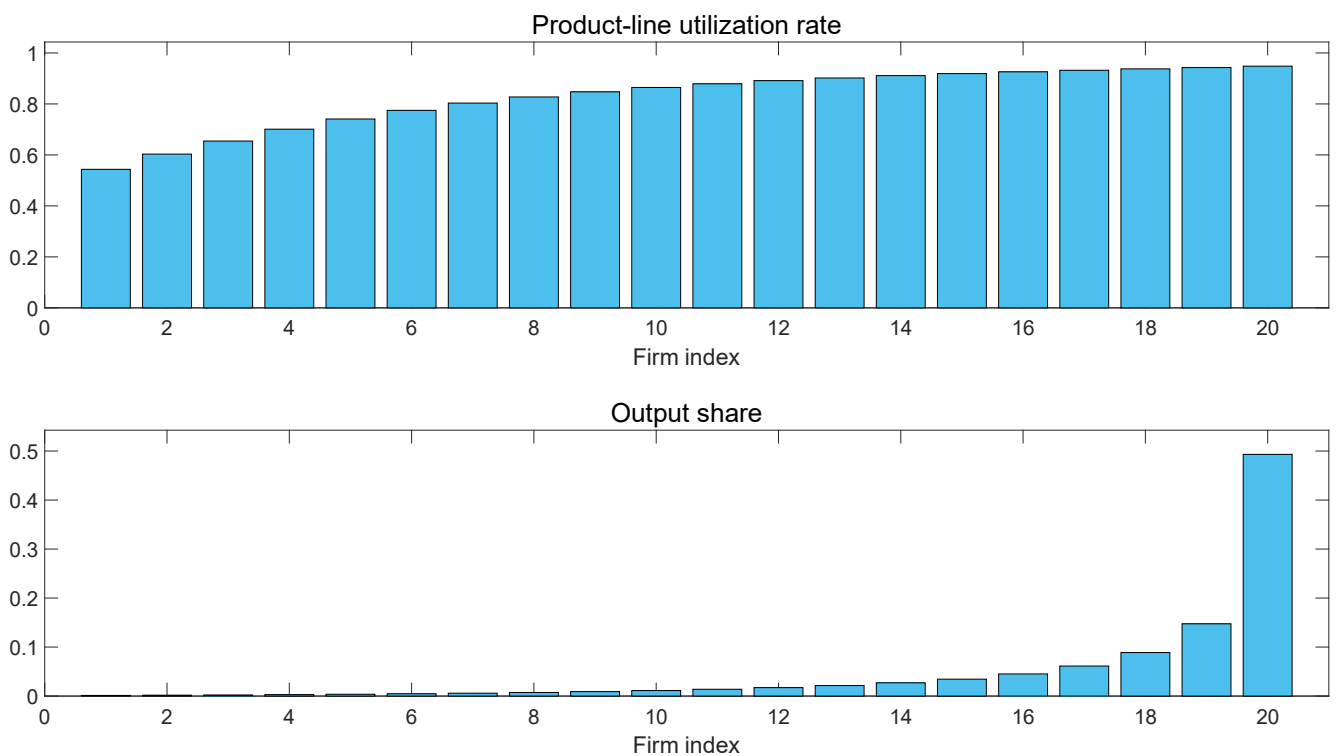

Figure 15: Product line utilization rate and output shares at the DSS

The top panels of Figures 14 and 15 prove that these substantial differences in output are mainly because high-productivity firms have more product lines and that a larger share of them are active. The difference in exogenous idiosyncratic productivity between the top $5 \%$ of "superstar firms" and the bottom 5\% of "lightweight firms" is $24 \%$. Yet, our model generates a ratio between the outputs of the top and bottom firms of 372 .

We can compare this result with a simple span-of-control model à la Lucas. With a production function $x l^{\gamma}$ where $x$ is managerial talent and $l$ is hours worked, the output ratio in such a model between two firms with $x=e^{-0.12}$ and $x=e^{0.12}$ (the same dispersion in managerial abilities than the dispersion in productivities in our model), is $e^{0.24 \frac{1}{1-\gamma}}$. To replicate an output ratio of 372, we would need $\gamma=0.96$, which is much higher than other estimates of returns to scale. For example, Atkeson and Kehoe (2005) argue that, in a span-of-control model, we should calibrate $\gamma=0.85$, while Guner et al. (2018) estimate an even lower $\gamma=0.77$. An alternative way to think about this is that a span-of-control model with $\gamma=0.96$ would generate differences in mTFP much larger than the ratio of 1.92 documented by Syverson (2011). 
Our results also challenges the predictions of the classic model of market power regarding excess capacity (an idea that goes back to Wicksell, 1934). That is, firms with market power operate under excess capacity in equilibrium. Figures 14 and 15 show that our model delivers the opposite result: top firms operate at a higher utilization rate, eliminating a key source of inefficiency in the economy - the more concentrated the market, the greater the rate of utilization of product lines.

\subsection{Monopsony power: market structure and wages}

We mentioned before that the role of monopsony power in driving market concentration is hard to gauge directly from Equation (42) because it affects $\widetilde{n}_{j}^{I}$ and $n_{j}^{I}$ nonlinearly. Thus, we show in Figure 16 the market structure at the DSS for three alternative degrees of threatening power $\widetilde{\delta}$ : 0.51 (our benchmark calibration), 0.75 , and 1 .
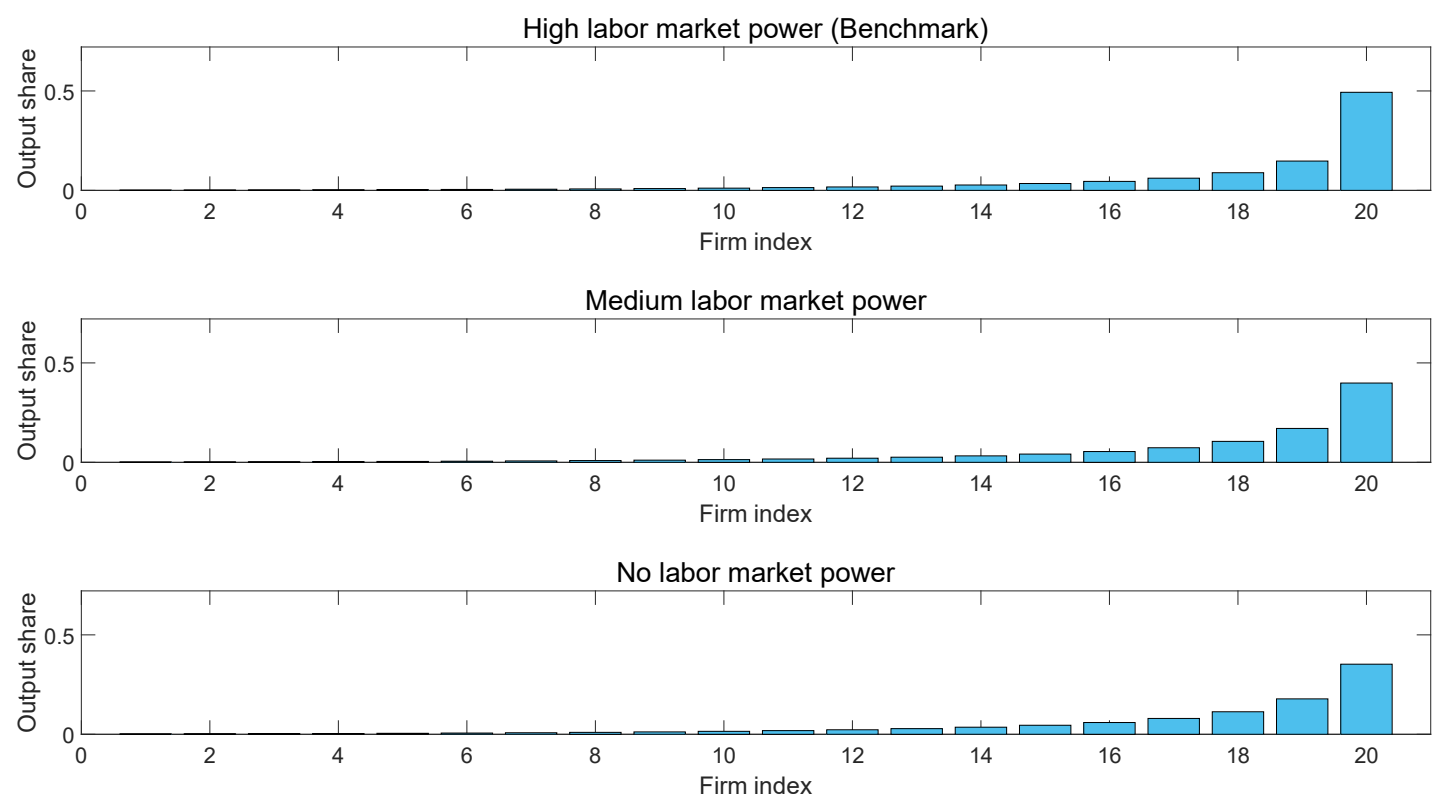

Figure 16: Market structure at the DSS

The top panel of Figure 16 is the same as the bottom panel of Figure 15: the top 10\% of firms produce $64.1 \%$ of output, our calibration target. The middle panel of Figure 16 documents that, as we increase $\widetilde{\delta}$ to 0.75 (equivalent to an average rate of forgiveness of 1.3 periods), the share of output of the top $10 \%$ of firms falls to $56.9 \%$. When we completely eliminate monopsony power (i.e., $\widetilde{\delta}=1$ ), the share of output of the top $10 \%$ of firms becomes $53.1 \%{ }^{7}$

\footnotetext{
${ }^{7}$ Figure 16 also illustrates Proposition 2: firms with a larger market share search more intensely, but this
} 
Figure 16 justifies our assertion in Section 4 that we can think about our model as a measurement device: the model tells how much monopsony power we need to account for market concentration that is consistent with mTFP, rate of idleness, and labor market observations. We find it intriguing that our model measures a moderate amount of monopsony power (a punishment that lasts only six months on average), but that such a monopsony power can increase market concentration at the top $10 \%$ of firms from $53.1 \%$ to $64.1 \%$ of output.

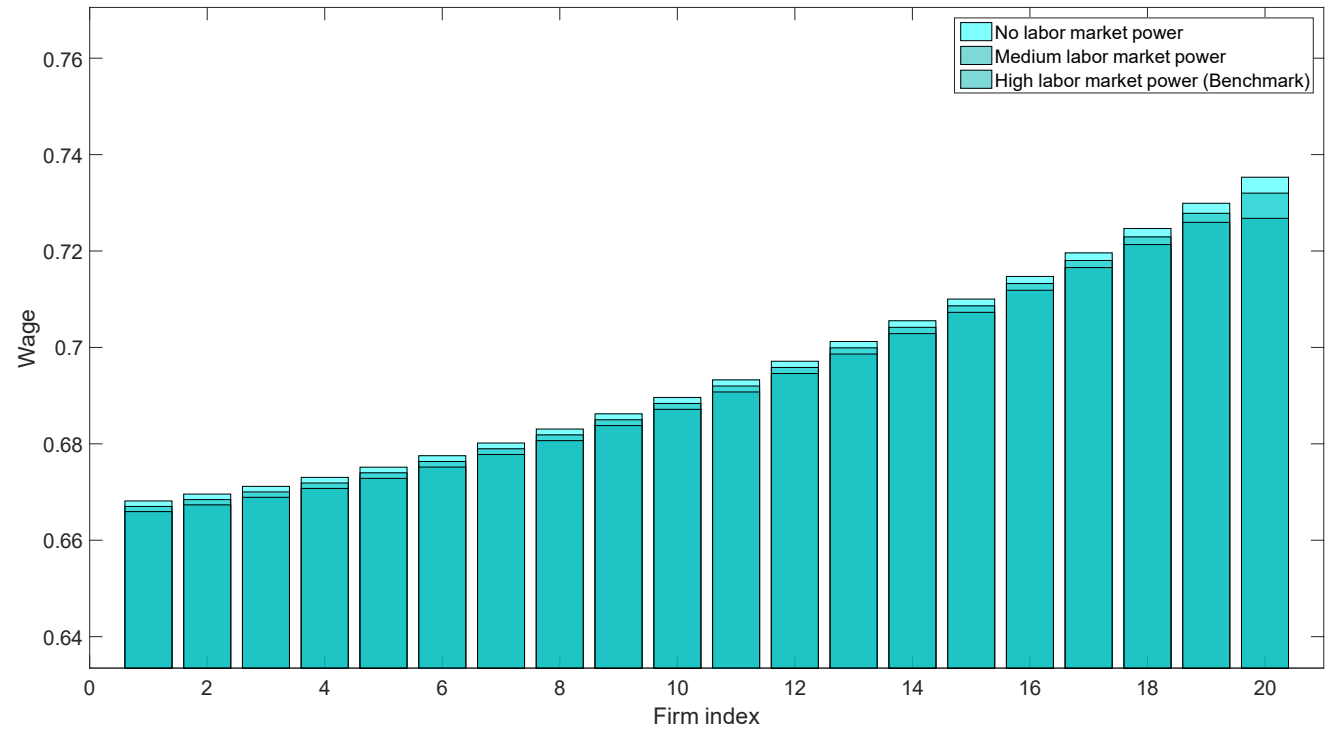

Figure 17: Wage with different labor market power

We move now to wages. In our model, monopsony power affects the wage distribution via two channels. In the first channel, the equilibrium wage decreases with the threatening power (i.e., increases with $\widetilde{\delta}$ ). We can see this effect in Figure 17, which plots the distribution of wages for $j$-type firms with high labor market power (dark-green histograms), medium labor market power (green histograms), and no labor market power cases (light-green histograms). As stated in Proposition 1, wages are increasing in the productivity of the firm, but decreasing with monopsony power. Moreover, the wage differential within the $j$-type firm is nonlinear: the more productive the firm, the stronger the threatening power and, therefore, the larger the share of the surplus kept by the firm.

Our result corroborates a large empirical literature on the negative effect of market concentration on wage compensation. For example, see Dube et al. (2016), Benmelech et al. (2018), Qiu and Sojourner (2019), and Naidu et al. (2018). Also, Berger et al. (2019) find that markdowns, intensity decreases with $\widetilde{\delta}$. 
the ratio between the marginal revenue product of labor and its wage, are increasing in firm size. Jarosch et al. (2019) show that employer market power is also boosted by search and matching frictions. Finally, Peters (2020) firms' market power is endogenous and the distribution of markups emerges as an equilibrium outcome.

The second channel through which monopsony power affects the wage distribution is that it reallocates workers toward high-productivity firms that have lower firm labor income shares. This last point is a standard feature of search and matching models. Intuitively, when a firm's productivity is sufficiently low, the firm still needs to compensate the workers that have the outside value of finding another job and receives zero profit. In this case, the labor income share is close to one. As we increase the firm's productivity, the outside value becomes less binding and the labor income share decreases. In addition, by reallocating workers toward high-productivity firms, monopsony power increases wage inequality.

These results agree with the empirical evidence. De Loecker et al. (2020) find that the decline in the economy-wide labor share is predominantly driven by large, high markup firms that have individually low labor shares. Similar findings are reported by Autor et al. (2020) and Kehrig and Vincent (2017).

But labor income share also falls when $\widetilde{\delta}$ decreases (i.e., we assume a higher threatening power). In our benchmark calibration $(\widetilde{\delta}=0.51)$, the labor income share is 0.66 and it increases to 0.663 when $\widetilde{\delta}=0.75$ and 0.667 when $\widetilde{\delta}=1$. While this effect is modest, we could substantially increase it if we were to assume (as it is likely to be the case in the real work) that high-

productivity firms also have a higher $\widetilde{\delta}$ (for example, through better HR processes to "punish" workers that do not accept low wage offers).

\subsection{Monopsony power without search complementarities}

We just saw how monopsony power in the labor market amplifies the effect of search complementarities on market concentration. But, does monopsony power generate market concentration in the absence of search complementarities? Yes, but the effect is mild.

To see this, we compute the market structure in the DSS model without search complementarities. To make our analysis comparable to our benchmark results, we fix all tightness ratios $\theta_{j, t}$ at their values in the benchmark DSS, but let the search effort $\left(\sigma_{j}^{I}\right)$ vary. Thus, when 
$\widetilde{\delta}=0.51$, the distribution of output shares across would be the same with or without search complementarities.
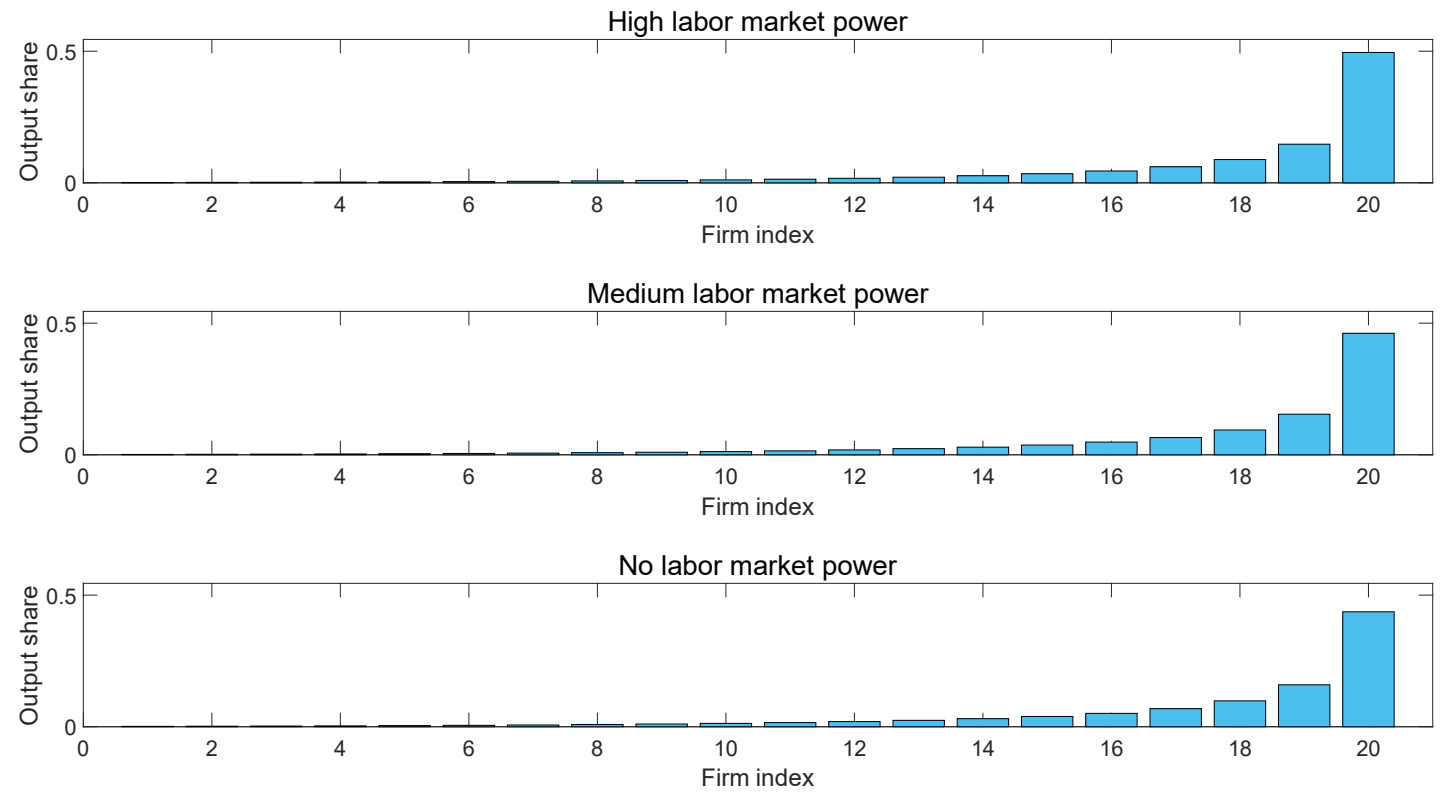

Figure 18: Market structure at the DSS with no search complementarity

Figure 18 shows the output shares for the same three levels of monopsony power as in Figure 16: 0.51 (our benchmark calibration), 0.75, and 1. By construction, the top panel of Figure 18 is identical to the top panel of Figure 16. The middle and lower panel of Figure 18 show that the role of monopsony power in market concentration becomes milder as the incentives to scale up production become smaller. For example, the top $5 \%$ of firms decrease their output share from $49.5 \%$ to $46.2 \%$ when $\widetilde{\delta}$ increases from 0.51 to 0.75 .

\subsection{Lower search costs increase market concentration}

We study the dependence of market structure on the cost of signing a vendor contract by considering a $5 \%$ permanent decline in the unit cost of visiting each submarket, $\kappa$, from 1 to 0.98. The bottom panel in Figure 19 shows our benchmark case of $\kappa=1$ while the top panel shows the firms' output when $\kappa=0.98$. A lower unit search cost induces all firms to search more actively, attracting a larger number of buying agents from sector $F$ to visit them, increasing the probability of forming a vendor relation and raising the number of product lines at the new DSS. However, the top $5 \%$ of "superstar firms" benefit the most from the reduction in $\kappa$, growing from producing $49.3 \%$ of output to producing $65.6 \%$. 

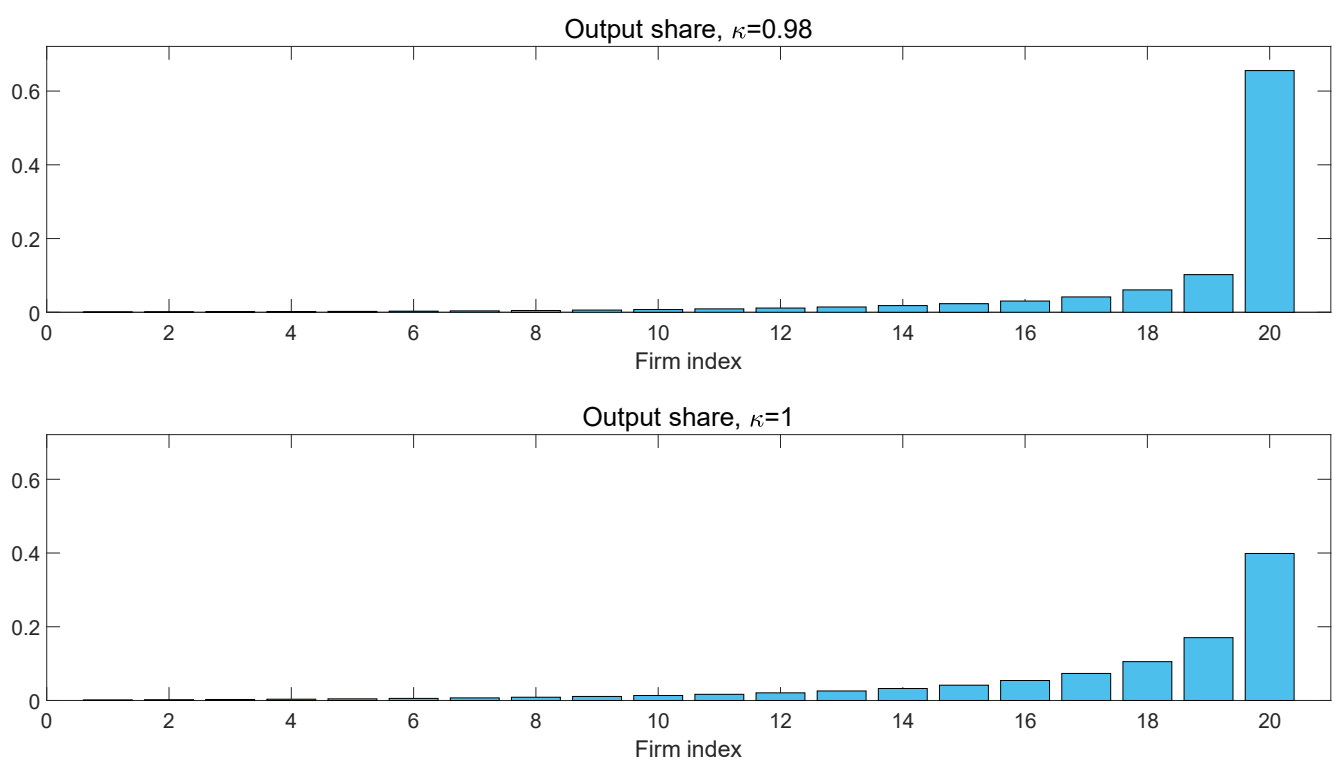

Figure 19: Output shares in DSS with different $\kappa$

As in the case of the basic model, we interpret these results as suggesting that improvements in IT over the last few decades (or, more generally, in the ability to scale up production) have been a critical factor behind the recent increase in market concentration documented by Autor et al. (2020) and others.

\subsection{Response of output to aggregate shocks}

Finally, we explore how the model responds to an aggregate shock. To do this, we implement a negative aggregate productivity shock, which reduces all firms' log-productivity. To reduce the computational burden of keeping track of 20 different types of firms, we slightly simplify our problem by assuming, for this subsection only, that the utility function of the household is linear in consumption.

Figure 20 shows the IFRs of the output of type-1 firms (the bottom 5\%; continuous blue line), the type-10 firms (the median firms; discontinuous black line), and the type-20 firms (the top 5\%; firms; discontinuous red line) to an aggregate shock that reduces log aggregate productivity by 10\%. Aggregate productivity reverts back to the steady state with a persistence of 0.95 . We express the IRFs in percentage deviations with respect to the DSS to allow for easier comparison.

At impact, all firms' output drops by $9.52 \%$. The recovery after this drop is slow because 
the productivity shock reduces firms' incentive to search. Thus, more product lines remain idle and they become obsolete at a higher rate. The process of product lines reduction is protracted and induces a lot of endogenous persistence in output.

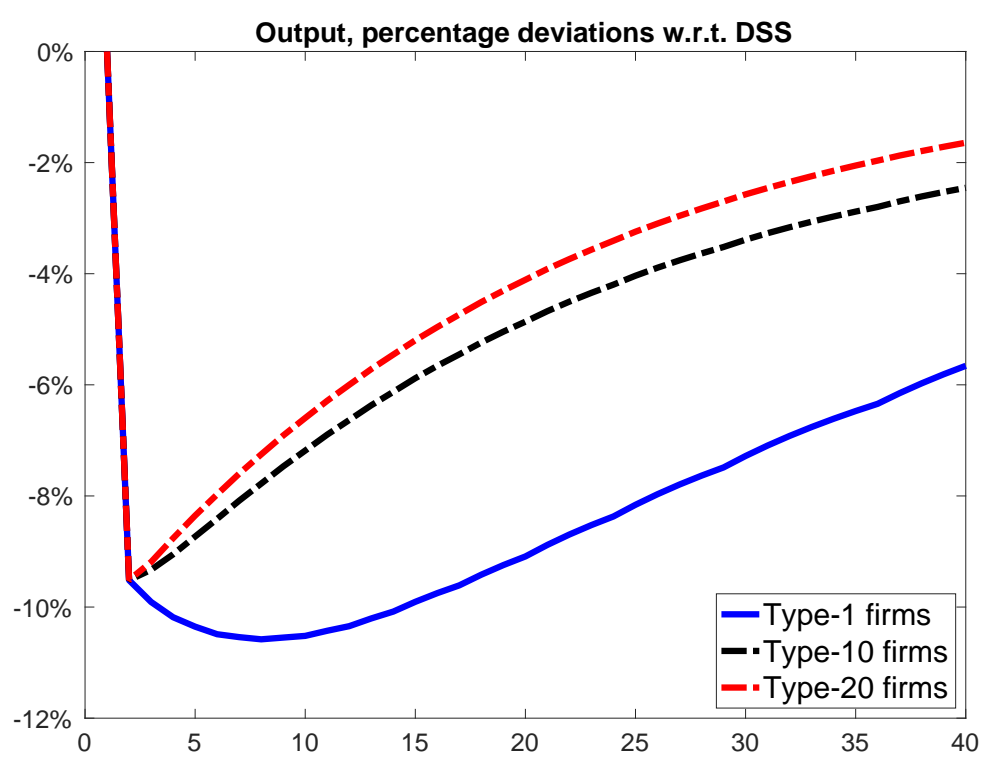

Figure 20: Response of output to $10 \%$ TFP shock

Interestingly, the recovery process is uneven across firms and increases market concentration. Specifically, it takes longer for low-productivity firms to recover. Intuitively, low-productivity firms' profit share is lower due to the worker's outside option of finding higher-paying jobs. Consequently, the low-productivity firms' search effort is more sensitive to productivity shocks, and these low-productivity firms lose more product lines in relative terms. In fact, for a few periods after the shock, the higher obsolescence rate of the non-active product lines of these low-productivity firms is such a powerful mechanism that their output continues dropping even if aggregate productivity is reverting to its mean. This mechanism accounts for the U-shaped IRF of low productivity firms. In comparison, high-productivity firms recover faster, and market concentration increases.

Our findings agree with Şahin et al. (2011), who documented, for example, that between December 2007 and December 2009, jobs declined 10.4\% in small firms (those with fewer than fifty employees), compared with $7.5 \%$ in large ones. These differences are close in magnitude to what we see in Figure 20.

Figure 20 also links our model with the Great Moderation of the U.S. economy after 1984. 
Since larger firms react less to negative aggregate shocks, the fall in search costs that we have argued above helps us understanding the growth in the size of superstar firms also helps us to account for the lower aggregate volatility of the economy.

\section{Conclusion}

Search complementarities have enormous consequences for market structure and the firm's size distribution. Through a "Matthew effect," small differences in productivity are transformed into large differences in firms' size, vacancies, and output. The key of this "Matthew effect" lies with the endogenous search decisions of intermediate- and final-goods producers under directed search: higher productivity leads to higher search effort by the intermediate-good producers and more buying agents by the final-goods producers. The presence of monopsony power in the labor market reinforces the process even more. The forces combine to generate superstar firms with output shares that match empirical observations.

Our model also suggests that a reduction in search costs (which can be more generally understood as a fall in the cost of scaling a business up) lead to i) higher market concentration; ii) lower labor income shares; and iii) more monopsony power by firms. We interpret the IT revolution since the 1980s in the U.S. and other advanced economies as a reduction in search costs (better logistics software, better inventory control, easier database management, etc.). Thus, our model offers a simple and parsimonious explanation of several important aspects of the data.

There is much scope for further investigation. We want to look at microdata to cross-validate the forces we highlight in our theoretical and quantitative analysis. We want to incorporate a firm's life-cycle. We want to think about innovation and technological adoption within the context of strategic complementarities. We want to think more about heterogeneity among different industry sectors. Are search costs as relevant in heavy manufacturing as in consumer services? Do the differences among industries in terms of market structure and the firm's size distribution align with our model? Finally, we also want to think about the policy implications of our model. We hope to explore some of these avenues of research shortly. 


\section{References}

Aghion, P., Bergeaud, A., Boppart, T., Klenow, P. J., and Li, H. (2019). A theory of falling growth and rising rents. Working Paper 26448, National Bureau of Economic Research.

Akerman, A., Helpman, E., Itskhoki, O., Muendler, M.-A., and Redding, S. (2013). Sources of wage inequality. American Economic Review, 103(3):214-219.

Ashenfelter, O., Farber, H., and Ransom, M. (2010). Labor market monopsony. Journal of Labor Economics, 28(2).

Atkeson, A. and Kehoe, P. (2005). Modeling and measuring organization capital. Journal of Political Economy, 113(5):1026-1053.

Autor, D., Dorn, D., Katz, L. F., Patterson, C., and Van Reenen, J. (2020). The fall of the labor share and the rise of superstar firms. Quarterly Journal of Economics, 135:645-709.

Azar, J., Huet-Vaughn, E., Marinescu, I. E., Taska, B., and Von Wachter, T. (2019). Minimum wage employment effects and labor market concentration. SSRN Scholarly Paper, Social Science Research Network, Rochester, NY.

Benmelech, E., Bergman, N., and Kim, H. (2018). Strong employers and weak employees: How does employer concentration affect wages? Working Paper 24307, National Bureau of Economic Research.

Berger, D. W., Herkenhoff, K. F., and Mongey, S. (2019). Labor market power. Working Paper 25719, National Bureau of Economic Research.

Bessen, J. E. (2017). Industry concentration and information technology. SSRN Scholarly Paper ID 3044730, Social Science Research Network, Rochester, NY.

Bulow, J. I., Geanakoplos, J. D., and Klemperer, P. D. (1985). Multimarket Oligopoly: Strategic Substitutes and Complements. Journal of Political Economy, 93(3):488-511.

Burdett, K. and Mortensen, D. T. (1980). Search, layoffs, and labor market equilibrium. Journal of Political Economy, 88(4):652-672.

Butters, G. R. (1977). Equilibrium distributions of sales and advertising prices. Review of Economic Studies, 44(3):465-491.

Card, D., Cardoso, A. R., Heining, J., and Kline, P. (2018). Firms and labor market inequality: Evidence and some theory. Journal of Labor Economics, 36(S1):S13 - S70.

Cette, G., Koehl, L., and Philippon, T. (2019). Labor shares in some advanced economies. Working Paper 26136, National Bureau of Economic Research.

Chevalier, J. A. and Scharfstein, D. S. (1996). Capital-market imperfections and countercyclical markups: Theory and evidence. American Economic Review, 86(4):703-725.

Covarrubias, M., Gutiérrez, G., and Philippon, T. (2019). From good to bad concentration? u.s. industries over the past 30 years. Working Paper 25983, National Bureau of Economic Research. 
De Loecker, J. and Eeckhout, J. (2018). Global market power. Working Paper 24768, National Bureau of Economic Research.

De Loecker, J., Eeckhout, J., and Unger, G. (2020). The rise of market power and the macroeconomic implications. Quarterly Journal of Economics, 135(2):561-644.

Diamond, P. (1982). Aggregate demand management in search equilibrium. Journal of Political Economy, 90(5):881-894.

Diamond, P. and Drew Fudenberg (1989). Rational expectations business cycles in search equilibrium. Journal of Political Economy, 97(3):606-619.

Dube, A., Lester, T. W., and Reich, M. (2016). Minimum wage shocks, employment flows, and labor market frictions. Journal of Labor Economics, 34(3):663-704.

Elsby, M., Hobijn, B., and Sahin, A. (2013). The decline of the U.S. labor share. Brookings Papers on Economic Activity, 44(2 (Fall)):1-63.

Falch, T. (2010). The elasticity of labor supply at the establishment level. Journal of Labor Economics, 28(2):237-266.

Fernández-Villaverde, J., Mandelman, F., Yu, Y., and Zanetti, F. (2019). Search complementarities, aggregate fluctuations, and fiscal policy. Working Paper 26210, National Bureau of Economic Research.

Garicano, L. and Rossi-Hansberg, E. (2006). Organization and Inequality in a Knowledge Economy*. The Quarterly Journal of Economics, 121(4):1383-1435.

Ghassibe, M. and Zanetti, F. (2020). State dependence of fiscal multipliers: the source of fluctuations matters. Mimeo, University of Oxford.

Guner, N., Parkhomenko, A., and Ventura, G. (2018). Managers and Productivity Differences. Review of Economic Dynamics, 29:256-282.

Gutiérrez, G. and Philippon, T. (2018). Ownership, concentration, and investment. AEA Papers and Proceedings, 108:432-437.

Hamano, M. and Zanetti, F. (2017). Endogenous turnover and macroeconomic dynamics. Review of Economic Dynamics, 26:263-279.

Hershbein, B., Macaluso, C., and Yeh, C. (2020). Monopsony in the U.S. labor market. Technical report, Working Paper.

Huo, Z. and Ríos-Rull, J.-V. (2013). Paradox of thrift recessions. Working Paper 19443, National Bureau of Economic Research.

Jarosch, G., Nimczik, J. S., and Sorkin, I. (2019). Granular search, market structure, and wages. Working Paper 26239, National Bureau of Economic Research.

Kaplan, G. and Menzio, G. (2016). Shopping externalities and self-fulfilling unemployment fluctuations. Journal of Political Economy, 124(3):771 - 825. 
Karabarbounis, L. and Neiman, B. (2014). The global decline of the labor share. Quarterly Journal of Economics, 129(1):61-103.

Kehrig, M. and Vincent, N. (2017). Growing Productivity without Growing Wages: The MicroLevel Anatomy of the Aggregate Labor Share Decline. CESifo Working Paper Series 6454, CESifo.

Lamadon, T., Mogstad, M., and Setzler, B. (2019). Imperfect competition, compensating differentials and rent sharing in the u.s. labor market. Working Paper 25954, National Bureau of Economic Research.

Lee, Y. and Mukoyama, T. (2015). Entry and exit of manufacturing plants over the business cycle. European Economic Review, 77:20-27.

Lucas, R. (1978). On the size distribution of business firms. Bell Journal of Economics, $9(2): 508-523$.

Manning, A. (2011). Imperfect competition in the labor market. In Ashenfelter, O. and Card, D., editors, Handbook of Labor Economics, volume 4B, chapter 11, pages 973-1041. Elsevier, 1 edition.

Manning, A. (2020). Monopsony in labor markets: A review. ILR Review.

Marinescu, I., Ouss, I., and Pape, L.-D. (2020). Wages, hires, and labor market concentration. Working Paper 28084, National Bureau of Economic Research.

Matsudaira, J. D. (2014). Monopsony in the low-wage labor market? Evidence from minimum nurse staffing regulations. Review of Economics and Statistics, 96(1):92-102.

Merton, R. K. (1968). The Matthew effect in science. Science, 159(3810):56-63.

Michaillat, P. and Saez, E. (2015). Aggregate demand, idle time, and unemployment. Quarterly Journal of Economics, 130(2):507-569.

Naidu, S., Posner, E. A., and Weyl, G. (2018). Antitrust remedies for labor market power. Harvard Law Review, 132:536.

Peters, M. (2020). Heterogeneous markups, growth, and endogenous misallocation. Econometrica, 88(5):2037-2073.

Petrongolo, B. and Pissarides, C. A. (2001). Looking into the black box: A survey of the matching function. Journal of Economic literature, 39(2):390-431.

Qiu, Y. and Sojourner, A. (2019). Labor-market concentration and labor compensation. Available at SSRN 3312197.

Ransom, M. and Sims, D. (2010). Estimating the firm's labor supply curve in a "new monopsony" framework: School teachers in missouri. Journal of Labor Economics, 28:331-355.

Şahin, A., Kitao, S., Cororaton, A., and Laiu, S. (2011). Why small businesses were hit harder by the recent recession. Current Issues in Economics and Finance, 17(4):1-7. 
Salgado, S., Guvenen, F., and Bloom, N. (2019). Skewed business cycles. Working Paper 26565, National Bureau of Economic Research.

Shimer, R. (2005). The cyclical behavior of equilibrium unemployment and vacancies. American Economic Review, 95:25-49.

Syverson, C. (2011). What determines productivity? Journal of Economic literature, 49(2):32665.

Taschereau-Dumouchel, M. and Schaal, E. (2015). Coordinating business cycles. 2015 meeting papers 178, Society for Economic Dynamics.

Thomas, C. and Zanetti, F. (2009). Labor market reform and price stability: An application to the Euro area. Journal of Monetary Economics, 56(6):885-899.

Unger, R. M. (2019). The Knowledge Economy. Verso Books.

Weitzman, M. (1982). Increasing returns and the foundations of unemployment theory. Economic Journal, 92(368):787-804.

Wicksell, K. (1934). Lectures on Political Economy. Macmillan Company.

Wu, L. (2019). Partially directed search in the labor market. University of Chicago, mimeo. 


\section{Appendix}

\section{Proof of Proposition 1}

In the deterministic steady state (DSS), ceteris paribus, the wage decreases with the firm's vacancy share $\left(s_{j}\right)$ and increases with the probability of forgiveness $(\widetilde{\delta})$

Proof. We begin our proof by showing that the ex-ante value of employment $W_{j}$ decreases with the firm's vacancy share, $s_{j}$, and it increases with the probability of forgiveness, $\widetilde{\delta}$. We denote the total surplus in a labor market without labor market power as:

$$
L T S_{j}^{*}=W_{j}-U+J_{j}-X_{j}
$$

so that the following equality holds:

$$
L T S_{j}=L T S_{j}^{*}+U-\widetilde{U}_{j}
$$

Equation (26) implies that:

$$
W_{j}=\widetilde{U}_{j}+(1-\widetilde{\tau}) L T S_{j}
$$

or, equivalently,

$$
W_{j}-U=(1-\widetilde{\tau}) L T S_{j}^{*}-\widetilde{\tau}\left(U-\widetilde{U}_{j}\right) .
$$

Equation (18) entails that:

$$
U-\widetilde{U}_{j}=\Gamma\left(s_{j}, \widetilde{\delta}\right)\left(W_{j}-U\right)
$$

with

$$
\Gamma\left(s_{j}, \widetilde{\delta}\right)=\frac{(1-\widetilde{\delta}) \beta s_{j} p^{u} p^{n}\left(W_{j}-U\right)}{1-\beta\left(1-p^{u}+s_{j} p^{u} p^{n}\right)(1-\widetilde{\delta})}
$$

Notice that $\partial \Gamma / \partial s_{j}>0$ and $\partial \Gamma / \partial \widetilde{\delta}<0$.

Substituting equation (44) into equation (43), it yields the following value for employment:

$$
W_{j}=U+\frac{1-\widetilde{\tau}}{1+\widetilde{\tau} \Gamma\left(s_{j}, \widetilde{\delta}\right)} L T S_{j}^{*}
$$

which implies that $W_{j}$ decreases with $s_{j}$, and it increases with $\widetilde{\delta}$. Since changes in $s_{j}$ or $\widetilde{\delta}$ determine the split of the total surplus between firms and workers, they involve a variation in $\Gamma\left(s_{j}, \widetilde{\delta}\right)$, and do not have a first-order effect on the value of $U$ and $L T S_{j}^{*}$.

Next, we show that the current period wage, $w_{j}$, decreases with $s_{j}$ and increases with $\widetilde{\delta}$. Equation (19) implies that:

$$
W_{j}=w_{j}+\beta\left[\left(1-\delta-\left(1-\pi_{j}\right) \chi\right) W_{j}+\left(\delta+\left(1-\pi_{j}\right) \chi\right) U\right],
$$


or:

$$
w_{j}=(1-\beta) W_{j}+\beta\left(\delta+\left(1-\pi_{j}\right) \chi\right)\left(W_{j}-U\right),
$$

which shows that $w_{j}$ strictly increases with $W_{j}$. Therefore, we have that $w_{j}$ decreases with $s_{j}$ and increases with $\widetilde{\delta}$.

\section{Proof of Proposition 2}

In the DSS, ceteris paribus, firm I's search effort increases with the firm's vacancy share $s_{j}$, and it decreases with the probability of forgiveness $\widetilde{\delta}$.

Proof. We begin our proof by showing that the value of a firm matched to a worker $\left(J_{j}\right)$ increases with $s_{j}$ and decreases with $\widetilde{\delta}$.

Equation (21) implies:

$$
X_{j}=\alpha_{X J} J_{j}
$$

where $\alpha_{X J}=\frac{\beta p^{n}}{1-\beta\left(1-p^{n}-\chi\right)}<1$. We rewrite equation (27) as:

$$
\left(1-\alpha_{X J}\right) J_{j}=\widetilde{\tau} L T S_{j}
$$

or, equivalently:

$$
J_{j}=\frac{\widetilde{\tau}}{1-\alpha_{X J}}\left(L T S_{j}^{*}+U-\widetilde{U}_{j}\right) .
$$

Substituting equations (44) and (46) into equation (49), it yields:

$$
J_{j}=\frac{\widetilde{\tau}}{1-\alpha_{X J}} \cdot \frac{(1-\widetilde{\tau}) \Gamma\left(s_{j}, \widetilde{\delta}\right)}{1+\widetilde{\tau} \Gamma\left(s_{j}, \widetilde{\delta}\right)} \cdot L T S_{j}^{*}
$$

where $\Gamma\left(s_{j}, \widetilde{\delta}\right)$ is defined by equation (45). Equation (50) implies that $J_{j}$ increases with $\Gamma(\cdot)$. Since $\partial \Gamma / \partial s_{j}>0$ and $\partial \Gamma / \partial \widetilde{\delta}<0, J_{j}$ increases with $s_{j}$, and decreases with $\widetilde{\delta}$. Consequently, equation (48) implies that $X_{j}$ increases with $s_{j}$ and decreases with $\widetilde{\delta}$. From equations (23) and (24), it is straightforward to show that $X_{j}^{I}=X_{j} / 2+\underset{\widetilde{J}}{\widetilde{J}_{j}^{I}} / 2$, which implies that $X_{j}^{I}$ increases with $X_{j}$, and it thus increases with $s_{j}$ and decreases with $\widetilde{\delta}$.

Next, we show that $\Delta J_{j}^{I}=X_{j}^{I}-(1-\chi) \widetilde{J}_{j}^{I}$ increases with $X_{j}^{I}$, and, thus, it increases with $s_{j}$ and decreases with $\widetilde{\delta}$. We prove $d \Delta J_{j}^{I} / d X_{j}^{I}>0$ in two steps.

In the first step, we show that $\widetilde{J}_{j}^{I}$ increases with $X_{j}^{I}$. Specifically, by denoting the optimal search effort with $\sigma^{*}$, and expressing $\widetilde{J}_{j}^{I}$ and $\sigma^{*}$ as functions of $X_{j}$, we re-write equation (30) in the DSS as:

$$
\widetilde{J}_{j}^{I}\left(X_{j}^{I}\right)=-c\left(\sigma^{*}\left(X_{j}^{I}\right)\right)+\beta\left[\pi_{j}^{I}\left(\sigma^{*}\left(X_{j}^{I}\right)\right) \cdot X_{j}^{I}+\left(1-\pi_{j}^{I}\left(\sigma^{*}\left(X_{j}\right)\right)\right) \cdot \widetilde{J}_{j}^{I}\left(X_{j}^{I}\right)\right],
$$


which we solve explicitly for $\widetilde{J}_{j}^{I}\left(X_{j}^{I}\right)$ :

$$
\widetilde{J}_{j}^{I}\left(X_{j}^{I}\right)=\frac{\beta \pi_{j}^{I}\left(\sigma^{*}\left(X_{j}^{I}\right)\right) \cdot X_{j}^{I}-c\left(\sigma^{*}\left(X_{j}^{I}\right)\right)}{1-\beta\left(1-\pi_{j}^{I}\left(\sigma^{*}\left(X_{j}\right)\right)\right)} .
$$

An increase of $X_{j}^{I}$ by $\Delta$ is equal to:

$$
\begin{aligned}
& \widetilde{J}_{j}^{I}\left(X_{j}^{I}+\Delta\right)=-c\left(\sigma^{*}\left(X_{j}^{I}+\Delta\right)\right)+ \\
& \quad \beta\left[\pi_{j}^{I}\left(\sigma^{*}\left(X_{j}^{I}+\Delta\right)\right) \cdot\left(X_{j}^{I}+\Delta\right)+\left(1-\pi_{j}^{I}\left(\sigma^{*}\left(X_{j}+\Delta\right)\right)\right) \cdot \widetilde{J}_{j}^{I}\left(X_{j}^{I}+\Delta\right)\right] \\
& \quad>-c\left(\sigma^{*}\left(X_{j}^{I}\right)\right)+\beta\left[\pi_{j}^{I}\left(\sigma^{*}\left(X_{j}^{I}\right)\right) \cdot\left(X_{j}^{I}+\Delta\right)+\left(1-\pi_{j}^{I}\left(\sigma^{*}\left(X_{j}\right)\right)\right) \widetilde{J}_{j}^{I}\left(X_{j}^{I}+\Delta\right)\right],
\end{aligned}
$$

which implies:

$$
\widetilde{J}_{j}^{I}\left(X_{j}^{I}+\Delta\right)>\frac{\beta \pi_{j}^{I}\left(\sigma^{*}\left(X_{j}^{I}\right)\right) \cdot\left(X_{j}^{I}+\Delta\right)-c\left(\sigma^{*}\left(X_{j}^{I}\right)\right)}{1-\beta\left(1-\pi_{j}^{I}\left(\sigma^{*}\left(X_{j}\right)\right)\right)} .
$$

By comparing equation (55) to equation (52), it shows that:

$$
\widetilde{J}_{j}^{I}\left(X_{j}^{I}+\Delta\right)>\widetilde{J}_{j}^{I}\left(X_{j}^{I}\right)
$$

clearly implying that $\widetilde{J}_{j}^{I}$ increases with $X_{j}^{I}$.

In the second step, we show that $\Delta J_{j}^{I}$ increases with $X_{j}^{I}$. From equation (30), we have that:

$$
\widetilde{J}_{j}^{I}=\frac{\beta \pi\left(\sigma_{j}\right) \Delta J_{j}^{I}-c\left(\sigma_{j}\right)}{1-\beta(1-\chi)} .
$$

We denote $G\left(X_{j}^{I}\right)=\beta \pi\left(\sigma_{j}\left(X_{j}^{I}\right)\right) \Delta J_{j}^{I}\left(X_{j}^{I}\right)-c\left(\sigma_{j}\left(X_{j}^{I}\right)\right)$, and we treat $\sigma_{j}$ and $\Delta J_{j}^{I}$ as functions of $X_{j}^{I}$. Since $\partial \widetilde{J}_{j}^{I} / \partial X_{j}^{I}>0$, the following holds:

$$
G^{\prime}\left(X_{j}^{I}\right)=\beta \pi^{\prime} \frac{d \sigma_{j}}{d X_{j}} \Delta J_{j}^{I}+\beta\left(\sigma_{j}\left(X_{j}^{I}\right)\right) \frac{d \Delta J_{j}^{I}}{d X_{j}^{I}}-c^{\prime} \frac{d \sigma_{j}}{d X_{j}}>0 .
$$

The optimality condition for firm I's problem (equation (30)) implies that:

$$
\beta \pi^{\prime} \Delta J_{j}^{I}-c^{\prime}\left(\sigma_{j}\right)=0,
$$

and by substituting equation (58) into equation (57), it yields:

$$
\frac{d \Delta J_{j}^{I}}{d X_{j}^{I}}>0
$$

which shows that $\Delta J_{j}^{I}$ increases with $X_{j}^{I}$, and consequently it increases with $s_{j}$ and decreases with $\widetilde{\delta}$. By using these findings in equation (33), we have that firm I's search effort increases with the firm's labor market share $s_{j}$ and decreases with the probability of forgiveness $\widetilde{\delta}$. 